\title{
Experimental investigation of the variability of concrete durability properties.
}

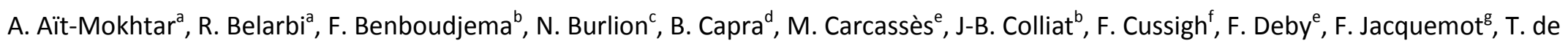

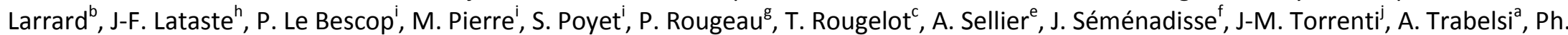
Turcry $^{\text {a }}$, H. Yanez-Godoy ${ }^{\mathrm{d}}$

a Université de La Rochelle, LaSIE FRE-CNRS 3474, Avenue Michel Crépeau, F-17042 La Rochelle Cedex 1, France.

b LMT/ENS Cachan/CNRS UMR 8535/UPMC/PRES UniverSud Paris, 61 Avenue du Président Wilson, F-94235 Cachan, France.

' Laboratoire de Mécanique de Lille, Boulevard Paul Langevin, Cité Scientifique, F-59655 Villeneuve d'Ascq Cedex, France.

${ }^{d}$ Oxand, 49 Avenue Franklin Roosevelt, F-77210 Avon / Fontainebleau, France.

e Université de Toulouse, UPS, INSA, LMDC (Laboratoire Matériaux et Durabilité des Constructions), 135 Avenue de Rangueil, F-31077 Toulouse Cedex 4, France.

${ }^{f}$ Vinci Construction France, Direction des Ressources Techniques et du Développement Durable, 61 Avenue Jules Quentin, F-92730 Nanterre Cedex, France.

${ }^{\mathrm{g}}$ CERIB, Rue des Longs Réages, BP 30059, F-28231 Epernon, France.

h Université Bordeaux 1, I2M CNRS UMR5295, Avenue des facultés, Bât. B18, F-33400 Talence, France.

'CEA, DEN, DPC, SECR, Laboratoire d'Etude du Comportement des Bétons et des Argiles, F-91191 Gif sur Yvette Cedex, France.

${ }^{j}$ Université Paris-Est, IFSTTAR, 58 Boulevard Lefebvre, F-75732 Paris Cedex 15, France.

\section{Abstract}


performance tests. Two construction sites were selected from which concrete specimens were periodically taken and tested by the different project partners. The obtained results (mechanical behavior, chloride migration, accelerated carbonation, gas permeability, desorption isotherms, porosity) are discussed and a statistical analysis was performed to characterize these results through appropriate probability density functions.

Keywords: concrete - durability indicators - performance tests - variability.

\section{Introduction / context}

The prediction of the service lifetime of new as well as existing concrete structures is a global challenge. Mathematical models are needed to assess to allow for a reliable prediction of the behavior of these structures during their lifetime. The French APPLET project was undertaken in order to improve these models and improve their robustness [1]. The main objectives of this project were to quantify the various sources of variability (material and structure) and to take these into account in probabilistic approaches, to include and to understand in a better manner the corrosion process, in particular by studying its influence on the steel behavior, to integrate knowledge assets on the evolution of concrete and steel properties in order to include interface models between the two materials, and propose relevant numerical models, to have robust predictive models to model the long term behavior of degraded structural elements, and to integrate the data obtained from monitoring or inspection.

Within this project, working group 1 (WG1) has taken into consideration the variability of the material properties for a probabilistic performance-based approach of the service lifetime prediction of concrete structures. This determination of the variability of various on site 
concretes was the subject of an experimental program with a significant number of tests allowing the characterization of indicators of durability or tests related to durability. After the presentation of the construction sites where the concrete specimens were produced in industrial conditions (using ready mix plants), the obtained results of the different tests (mechanical behavior, chloride migration, carbonation, permeability, desorption isotherms, porosity) are discussed and probability density functions are associated to these results.

\section{Case studies}

The objective of the project was the characterization of the variability of concretes produced in industrial conditions. This variability is due to the natural variability of the constituents of concrete, to errors in constituents weighing, to quality of vibration and compaction, to the initial concrete temperature, to environmental conditions, etc. For the supply of specimens, the project takes advantage from the support of Vinci Construction France. Two construction sites where two concretes were prepared continuously during at least 12 months regularly provided specimens to the various participants for the execution of their tests: works for the south tunnel in Highway A86 (construction site A1) and for a viaduct near Compiègne (north of Paris - construction site A2). provided with a frequency of about one week. The concrete was a C50/60 (characteristic compressive strength at 28 days) containing Portland cement (CEM I) and fly-ashes used for the construction of the slab separating the two lanes from the tunnel of Highway A86 (Table 1). The concrete was prepared using the concrete plant on site by the site workers. Forty batches were made on this first construction site. The last specimen was cast on the $31^{\text {st }}$ March 2008. In fact, for each date, 15 specimens (cylinders with a diameter of $113 \mathrm{~mm}$ and a height of $226 \mathrm{~mm}$; 

produced and dispatched to the 7 laboratories participating in the project.

At the second construction site a concrete C40/50 was produced containing CEM III cement which was used for the construction of the 61 supports (foundations, piles) of the viaduct of Compiegne (Table 1). The first specimens (A2-1) were produced the $6^{\text {th }}$ of November 2007 at the viaduct construction site. The concrete was also prepared by the site workers using a ready mix concrete. However, from batch A2-21 on, due to work constraints another composition corresponding to the same concrete quality was used to improve the concrete workability (denoted A2/2).

Table 1 - Concrete mixes (per $\mathrm{m}^{3}$ of concrete).

\begin{tabular}{|c|c|c|c|}
\hline Site & A1 & A2/1 & A2/2 \\
\hline Cement C & CEM I $52.5-350 \mathrm{~kg}$ & \multicolumn{2}{|c|}{ CEM III/A 52.5L LH - 355 kg } \\
\hline Additions A & Fly ash $-80 \mathrm{~kg}$ & $176 \mathrm{~L}$ & Calcareous filler - 50 kg \\
\hline Water W & $177 \mathrm{~L}$ & 0.50 & $193 \mathrm{~L}$ \\
\hline W/C & 0.51 & 0.54
\end{tabular}

68

It must be added here that all the specimens used in this project were prepared on the two sites by the site workers simultaneously to the fabrication of the slabs and supports of the construction sites $A 1$ and $A 2$, respectively. In the authors' mind, the concrete specimens are then made of "realcrete" and are believed to be more or less representative of the materials that can be encountered within the considered structures. Nonetheless it must be kept in mind that the variability obtained in this study might just be a rough estimate of the variability of the 
corresponding structural elements because the impact of some worksite features (for instance presence of reinforcement, structural element dimensions and height of chute) could not be reproduced using small specimens.

\section{Experimental results}

\subsection{Compressive and tensile strengths}

This part of the research aims at proposing a characterization of the mechanical behavior of each studied batch by standard tests to determine the tensile strength (by a splitting test), and also the compressive strength and Young's modulus (through a compression test). The tests were performed at LMT of the Ecole Normale Supérieure de Cachan. For each batch, a cylindrical $113 \times 226 \mathrm{~mm}$ specimen is devoted to compression test, while the splitting test is performed on a cylindrical specimen of $113 \mathrm{~mm}$ in diameter and $170 \mathrm{~mm}$ in height (the upper part of the specimen is used for porosity and pulse velocity measurements).

For the compression test, the specimen is mechanically grinded before being placed in press. The specimen is equipped with an extensometer (three LVDTs positioned at 120 degrees attached to a metal ring, which is fixed on the concrete specimen by set screws) to measure the longitudinal strain of the specimen during the loading phase assumed to be elastic, between 5 and $30 \%$ of the failure load in compression. Three cycles of loading and unloading are performed in the elastic behavior region of the concrete, with a loading rate of $5 \mathrm{kN} / \mathrm{s}$ (the rate is the same

for unloading). Young's modulus is determined by linear regression on five points placed on the curve corresponding to the third unloading, according to the protocol proposed by [2]. Then, after removing the extensometer, the specimen is loaded until failure. 

coefficient of variation ${ }^{1}$ and number of specimens tested). It can be observed that the compressive strength is much higher than expected according to the compressive strength class and to the achieved values of compressive strength at 28 days (measured on site). This is due to the fact that the specimens were tested after one year of curing in saturated lime water resulting in a higher hydration degree which improves the observed for Young's modulus is significantly lower (between 5 and 7\%).

95

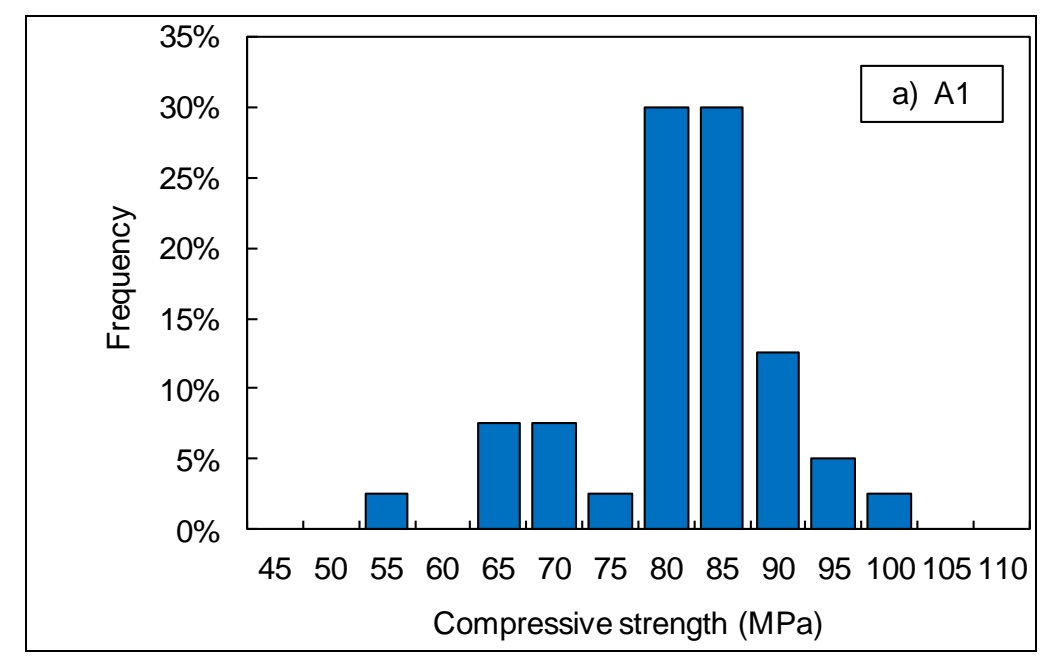

\footnotetext{
${ }^{1}$ The coefficient of variation (COV) is defined as the ratio of the standard deviation to the mean value. It is an indicator of the dataset dispersion.
} 


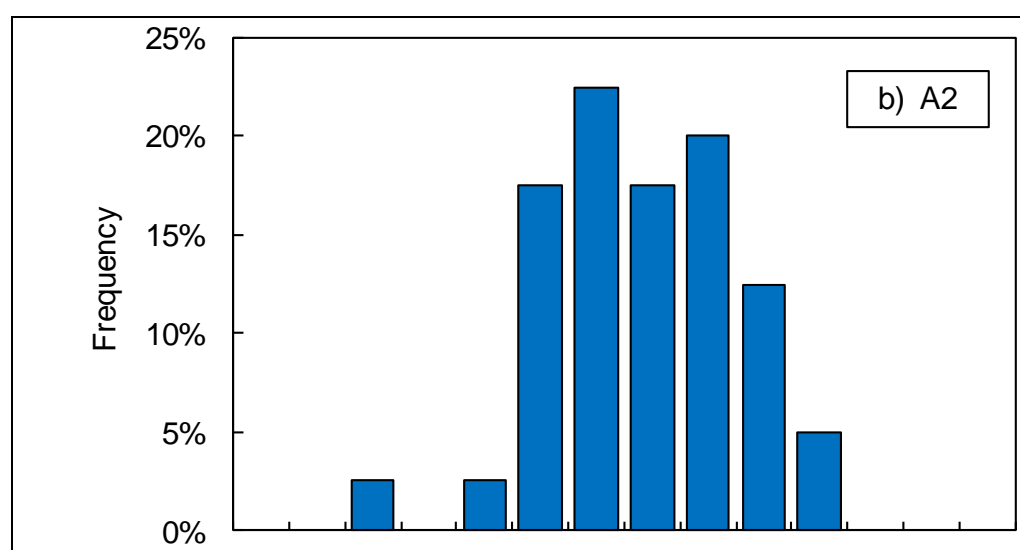

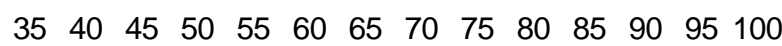
Compressive strength (MPa)

Figure 1 - Distribution of the compressive strength measured in laboratory (LMT) after 1 year curing.

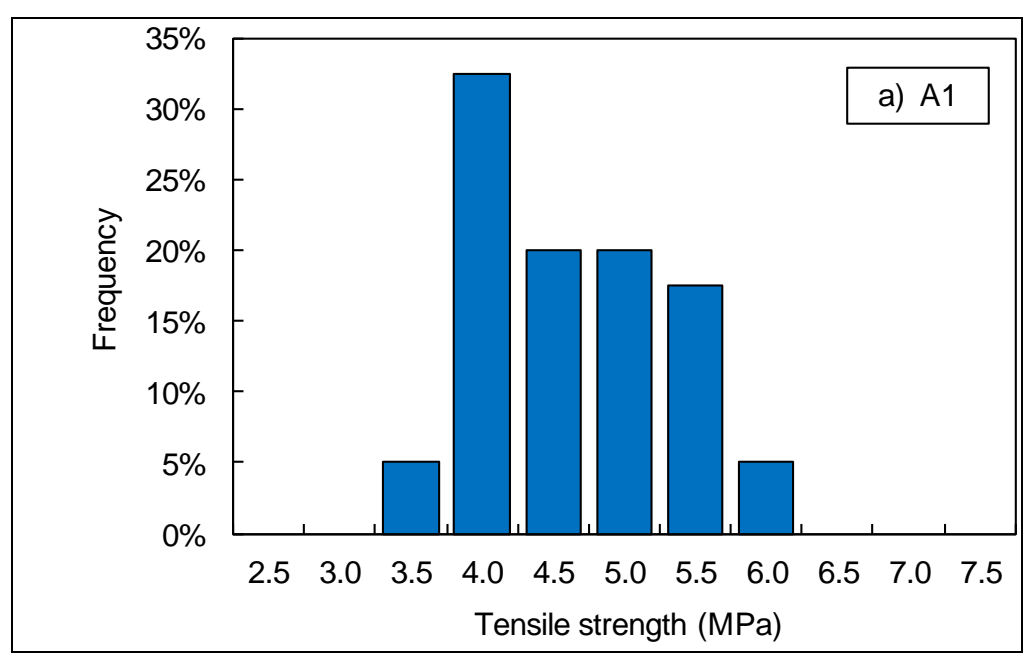




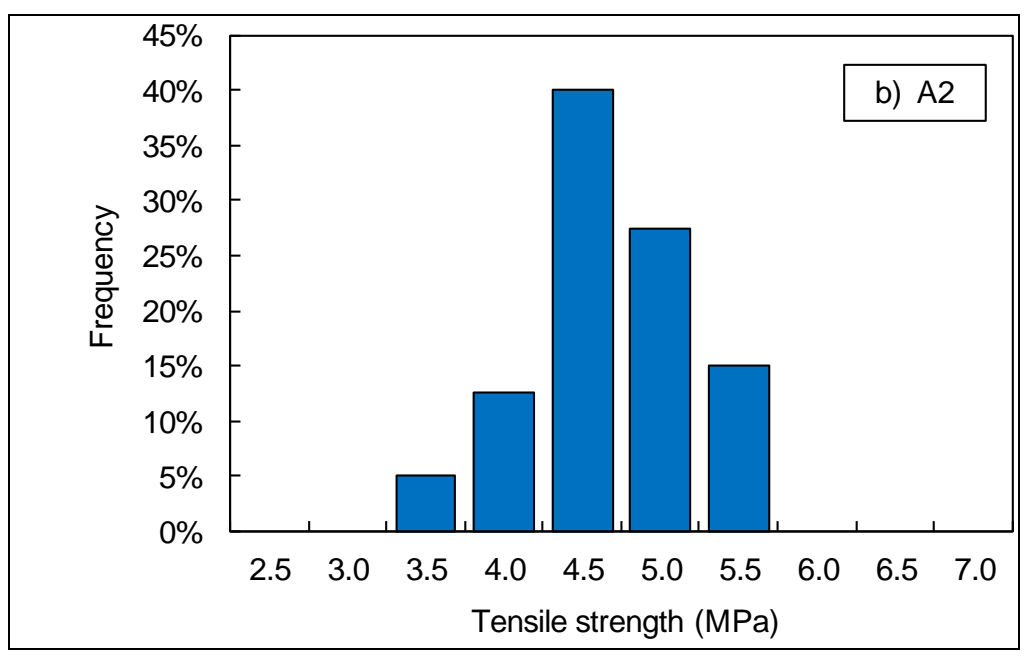

Figure 2 - Distribution of the tensile strength measured in laboratory (LMT) after 1 year curing.

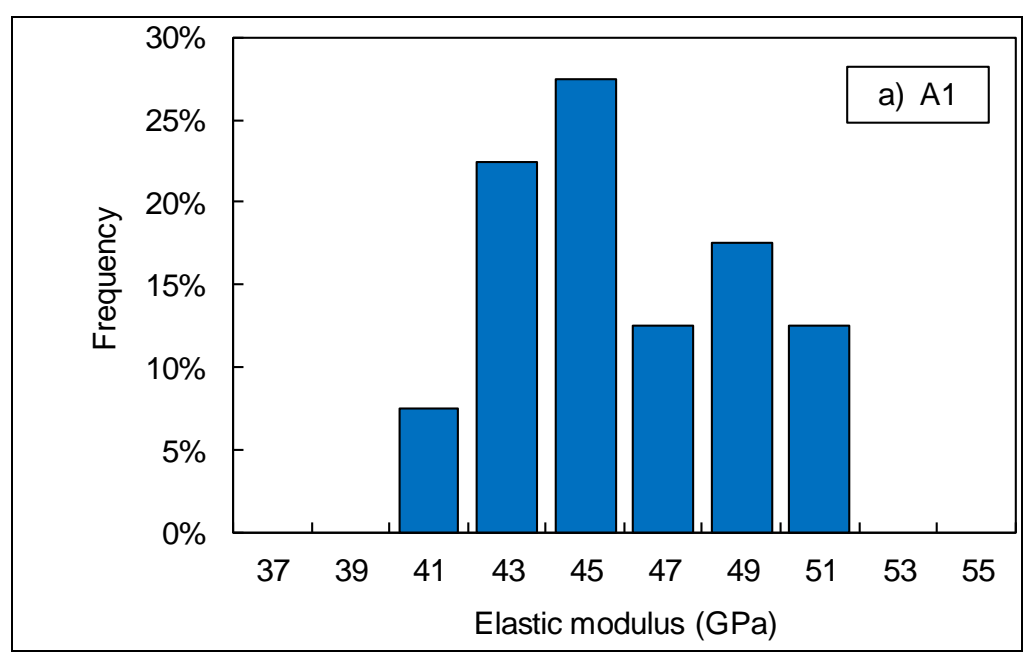




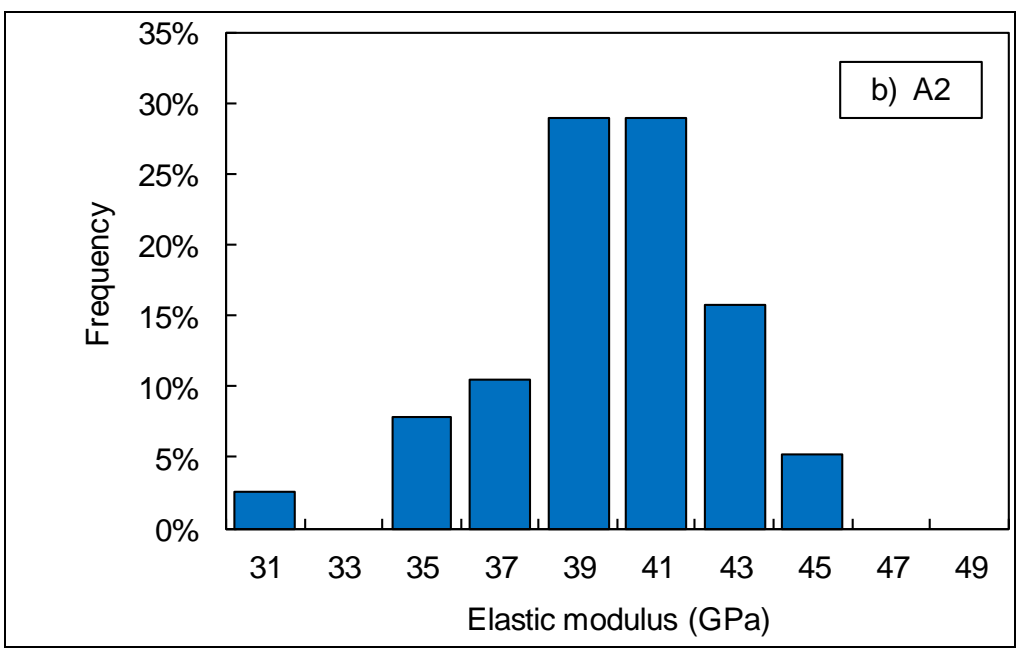

Table 2 - Mechanical tests for 3 concrete mix designs: mean values, coefficient of variation and number of specimens tested for the compressive $\left(f_{c}\right)$ and tensile $\left(f_{t}\right)$ strengths and Young's modulus $(E)$.

\begin{tabular}{|c|c|c|c|c|c|c|c|}
\hline \multirow{2}{*}{ Site } & \multirow{2}{*}{ Number } & \multicolumn{2}{|c|}{$f_{c}[\mathrm{MPa}]$} & \multicolumn{2}{|c|}{$f_{t}[\mathrm{MPa}]$} & \multicolumn{2}{c|}{$E[\mathrm{GPa}]$} \\
\cline { 3 - 8 } & & Mean & COV (\%) & Mean & COV (\%) & Mean & COV (\%) \\
\hline A1 & 40 & 83.8 & 10.5 & 4.9 & 13.2 & 46.8 & 6.2 \\
\hline A2-1 & 20 & 75.6 & 11.3 & 5.1 & 9.7 & 40.8 & 7.0 \\
\hline A2-2 & 20 & 68.2 & 9.0 & 4.8 & 9.3 & 40.8 & 5.4 \\
\hline
\end{tabular}



results obtained for the variability are very similar to the previous ones (Table 3 and Figure 4).

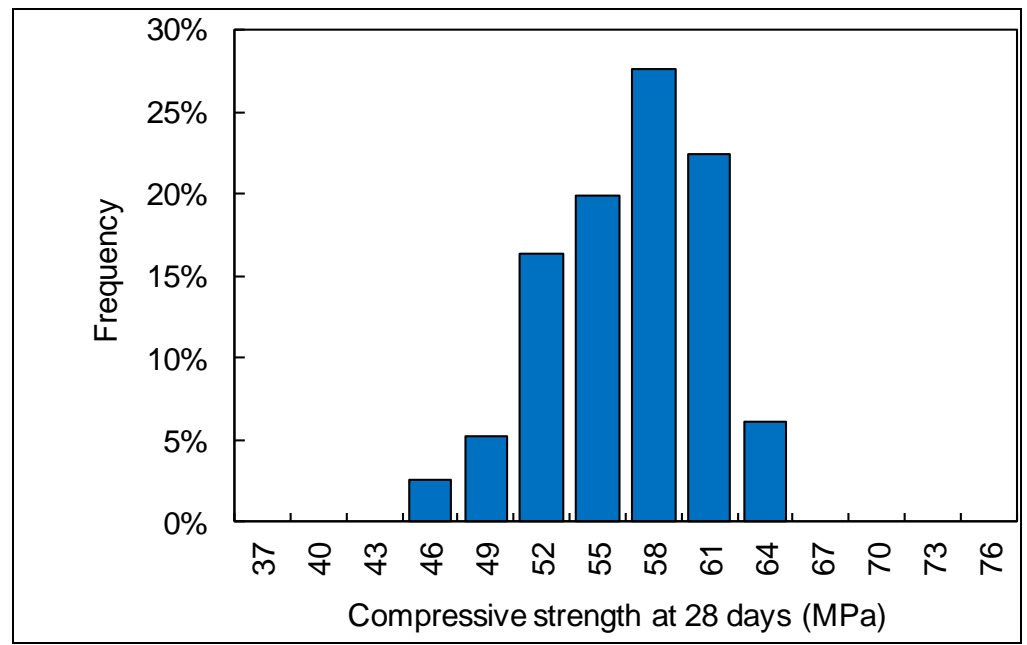




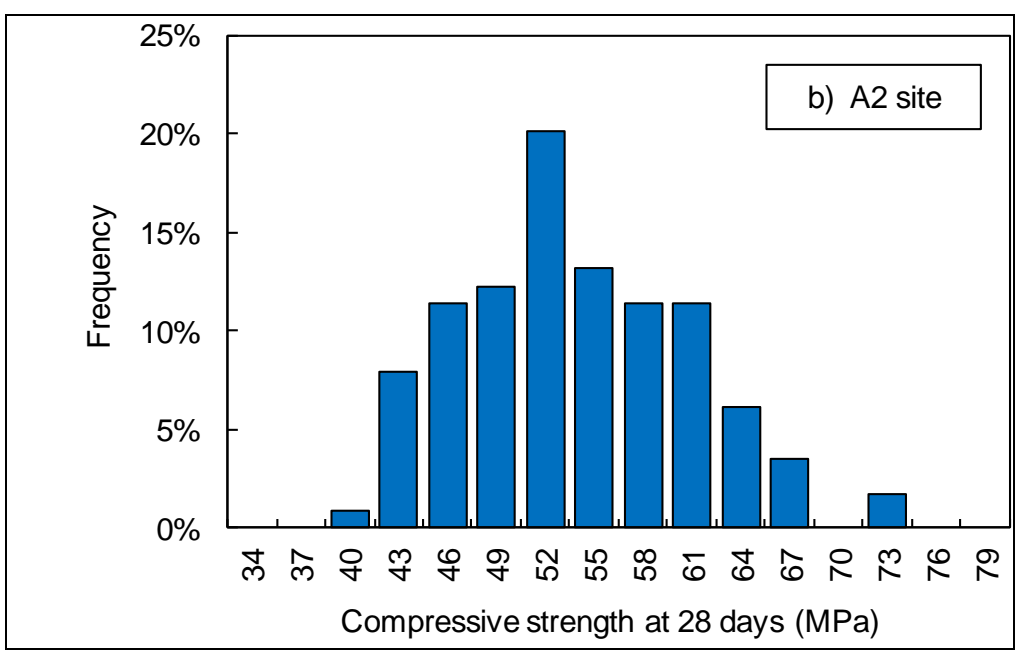

Table 3 - Compressive strength measured on site by Vinci Construction France: number of tests (Nb), mean value and coefficient of variation Figure 4 - Distribution of the compressive strength (at 28 days) measured on site by Vinci Construction France.

Table 3- Compressive strength measured on site by Vinci Construction France: number of tests
(COV).
\begin{tabular}{|c|c|c|c|}
\hline \multirow{2}{*}{ Site } & \multirow{2}{*}{$\mathrm{Nb}$} & \multicolumn{1}{|c|}{$f_{c}[\mathrm{MPa}]$} \\
\cline { 3 - 5 } & & Mean & COV (\%) \\
\hline $\mathrm{A} 1$ & 40 & 58.2 & $7.3 \%$ \\
\hline $\mathrm{A} 2-1$ & 20 & 57.8 & $11.1 \%$ \\
\hline $\mathrm{A} 2-2$ & 20 & 52.6 & $11.1 \%$ \\
\hline
\end{tabular}

\subsection{Chloride migration}




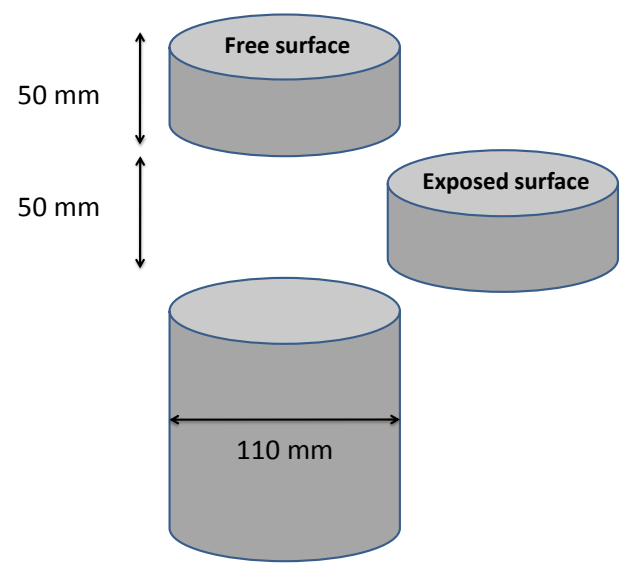


which receives the sleeve) corresponds to the upstream compartment. The upper compartment contains the catholyte solution, i.e. a solution of $10 \%$ sodium chloride by mass (about 110 grams per liter) whereas the downstream compartment is filled with the anolyte solution, $0.3 \mathrm{M}$ sodium hydroxide. These solutions are stored in the conditioned test room at $20^{\circ} \mathrm{C}$. In each compartment an electrode is immersed, which is externally connected through a voltage source so that the cathode, immersed in the chloride solution, is connected to the negative pole and the anode, placed in the extending part of the sleeve, is connected to the positive pole. An initial voltage of $30 \mathrm{~V}$ is applied to the specimen. This voltage is then adjusted to achieve a duration test of 24 hours depending on the magnitude of the current flowing through the cell as a result of the initial voltage of $30 \mathrm{~V}$. The correction is proposed in the standard NT Build 492 [7]. For A1 specimens, for the entire series the voltage used for the test is $35 \mathrm{~V}$ whereas $50 \mathrm{~V}$ is applied for the entire $\mathrm{A} 2$ series.

After 24 hours, the specimen is removed to be split in two pieces. Silver nitrate $\mathrm{AgNO}_{3}$ is then sprayed onto the freshly fractured concrete surface. The white precipitate of silver chloride appears after ten minutes revealing the achieved chloride penetration front. At the concrete surface where chlorides are not present silver nitrate will not precipitate but will quickly oxidize and then turn black after a few hours. The chloride penetration depth in concrete $x_{d}$ is then measured using a slide caliper using an interval of $10 \mathrm{~mm}$ to obtain 7 measured depths. To avoid edge effects, a distance of $10 \mathrm{~mm}$ is discarded at each edge. Moreover, if the front ahead of a measuring point is obviously blocked by an aggregate particle, then the associated measured depth is rejected. Then the migration coefficient $D_{n s s m}$ (non steady state migration) $\left(\mathrm{m}^{2} / \mathrm{s}\right)$ is calculated using the following formula:

153

$$
D_{n s s m}=\frac{0.0239(273+T) \cdot L}{(U-2) t}\left(x_{d}-0.0238 \sqrt{\frac{(273+T) L x_{d}}{U-2}}\right)
$$



coefficient obtained for the specimens from the A1 series. easily explained by the formulation of this $\mathrm{C} 50 / 60$ concrete where fly ash was used, which is known to significantly reduce the diffusion

161 coefficient [8]. The minimum value observed is $3.11 \times 10^{-12} \mathrm{~m}^{2} / \mathrm{s}$ and the maximum amounts to $5.59 \times 10^{-12} \mathrm{~m}^{2} / \mathrm{s}$ which corresponds to a ratio of

162 1.8. The difference may seem relevant but basically corresponds to a divergence in concrete porosity of about $1.5 \%$ if the migration coefficients

163 are estimated from basic models [9]. The standard deviation is equal $0.53 \times 10^{-12} \mathrm{~m}^{2} / \mathrm{s}$; this corresponds to a coefficient of variation of $12.4 \%$

\section{4 (Table 4).}




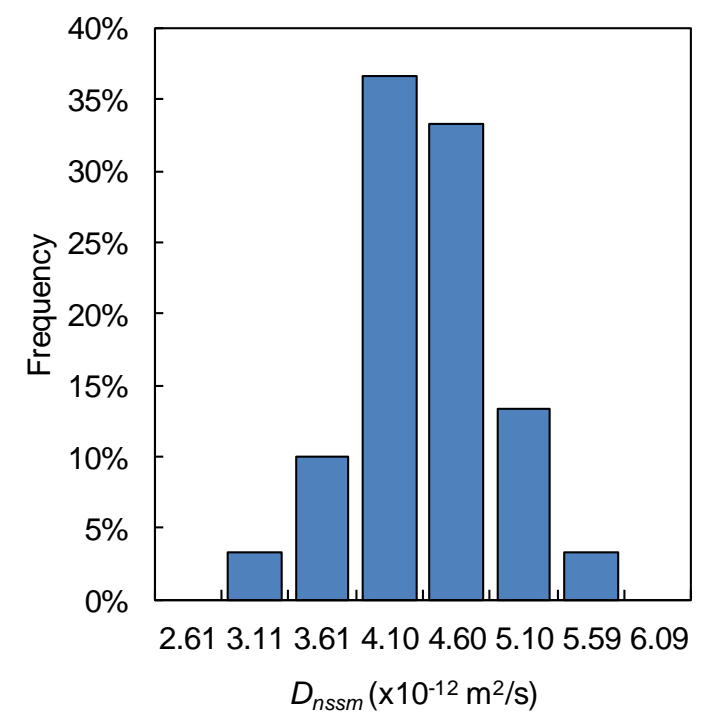
A2-21, which corresponds to the modified mix design of the A2 series. The mean migration coefficients determined for the complete A2 series is $1712.53 \times 10^{-12} \mathrm{~m}^{2} / \mathrm{s}$ with a standard deviation of $0.55 \times 10^{-12} \mathrm{~m}^{2} / \mathrm{s}$ corresponding to a coefficient of variation of $21.9 \%$. Compared to the concrete of the A1 series, the resistance of this concrete against chloride ingress is significantly higher. The average value is even smaller however for this $A 2$ series concrete specimens were tested at a later age, i.e. one year instead of three months for A1. The second concrete (A2) would certainly achieve more modest results at a younger age because of the slow hydration kinetics for this type of cement containing blast furnace slag. formulations, the results must be treated in two subsets. In addition, the first formulation contains only 11 results, whereas the histogram of the 

series amounts to $2.45 \times 10^{-12} \mathrm{~m}^{2} / \mathrm{s}$ with a standard deviation of $0.47 \times 10^{-12} \mathrm{~m}^{2} / \mathrm{s}$, which corresponds to a coefficient of variation of $19.4 \%$ (Table 4 ).

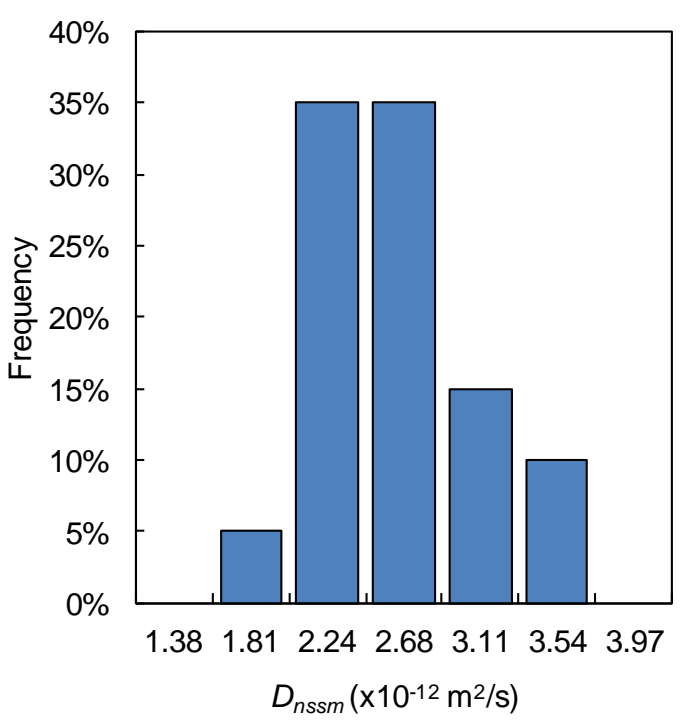

Figure 7 - Histogram of the migration coefficient for the A2-2 series.

The variability is higher than for the A1 series since the coefficient of variation increases from $12.4 \%$ to $19.5 \%$ (and even larger if A2-1 consider is considered). 


$$
\frac{m(t)-m(t+24 h)}{m(t+24 h)} \leq 0.005 \%
$$


where $m(t)$ is the mass measured at the moment $t$ and $m(t+24 \mathrm{~h})$ is the measured mass 24 hours later.

The test started with specimens which were initially saturated. To achieve the saturation, the adopted procedure consists in storing the cylindrical specimens $\emptyset 113 \times 226 \mathrm{~mm}$ under water one day after mixing during at least 4 months. Besides, this procedure promotes a high degree of hydration of cement. At the age of 3 months, these specimens were sawn in discs of $113 \mathrm{~mm}$ diameter and $5 \pm 0.5 \mathrm{~mm}$ thickness. In these discs a $4 \mathrm{~mm}$ diameter hole was drilled allowing mass measurements to be made inside the controlled RH environment with an accuracy of 0.001 composition (i.e. A2-1) was studied with 3 specimens per batch and overall, 180 specimens were studied.

Figure 8 shows the isothermal desorption curves for compositions A1 and A2-1. The water contents at equilibrium for the different RH levels were calculated on the basis of dry mass measured at the equilibrium state for $3 \% \mathrm{RH}$. The so-obtained desorption isotherms belong to type IV according to the IUPAC classification [13]. These are characterized by two inflections which are often observed for such a material [12]. Desorption is thus multi-molecular with capillary condensation over a broad interval, which highlights a pore size distribution with several modes (i.e. with several inflections points. For a given $\mathrm{RH}$, concrete mixture A2-1 has higher average water content, especially for $\mathrm{RH}$ levels above $50 \%$. 


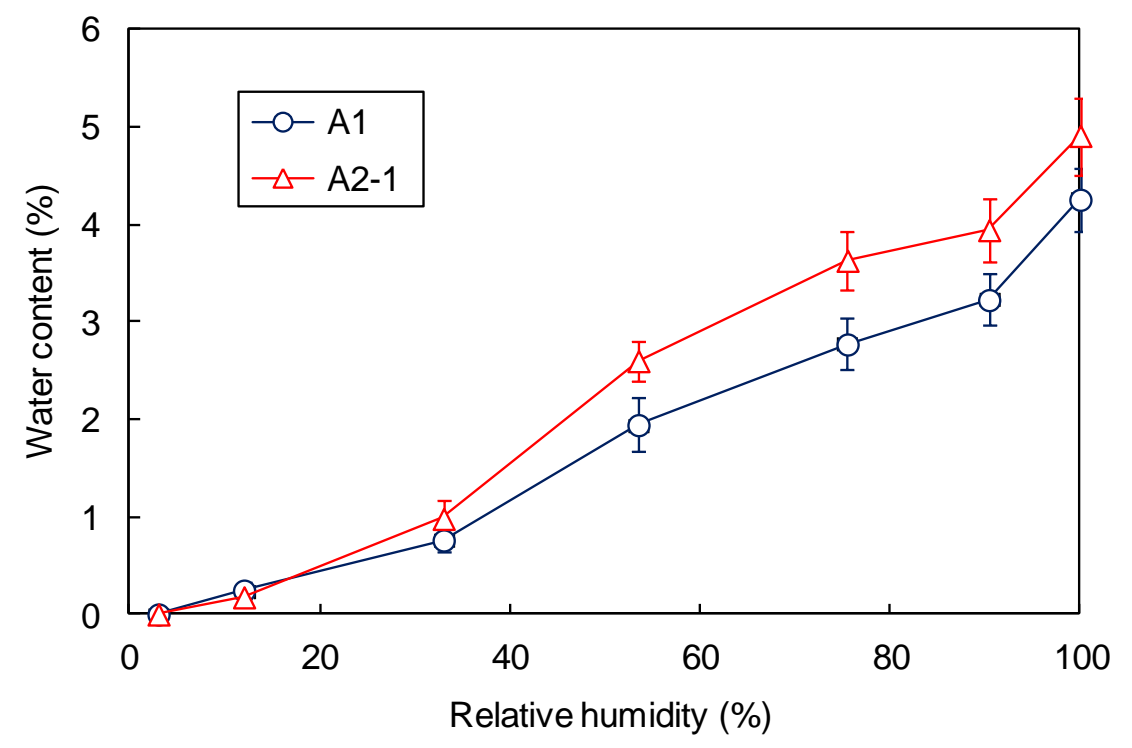

Figure 8 - Average isothermal desorption curves for mixtures A1 and A2-1. corresponding standard deviations and coefficients of variation. The coefficient of variation for 3 specimens from a single batch is approximately equal to $10 \%$ for $\mathrm{RH}$ levels between 100 and $33 \%$ and equal to $20 \%$ for $\mathrm{RH}=12 \%$. The coefficients of variation determined over the complete construction period (given in Table 5) are higher than the coefficients of variation for a single batch. The observed dispersion is not only due to the randomness of test measurements, but also due to variability of material properties under site conditions [14]. It should be recalled that mixtures were made in real ready-mix concrete plants. 
Table 5 - Water vapour desorption isotherm: average values, standard deviations (Std dev.) and coefficients of variations (COV) of water contents at equilibrium (throughout the construction period).

\begin{tabular}{|c|c|c|c|c|c|c|c|}
\hline Concrete & $\mathrm{RH}$ & $12 \%$ & $33 \%$ & $53.5 \%$ & $75.5 \%$ & $90.4 \%$ & $100 \%$ \\
\hline \multirow{3}{*}{ A1 } & Mean (\%) & 0.2 & 0.8 & 1.9 & 2.8 & 3.2 & 4.3 \\
\cline { 2 - 8 } & Std dev. (\%) & 0.09 & 0.13 & 0.27 & 0.27 & 0.26 & 0.33 \\
\cline { 2 - 8 } & COV (\%) & 45 & 16 & 14 & 10 & 8 & 8 \\
\hline \multirow{3}{*}{ A2-1 } & Mean (\%) & 0.2 & 1.0 & 2.6 & 3.6 & 3.9 & 4.9 \\
\cline { 2 - 8 } & Std dev. (\%) & 0.08 & 0.17 & 0.18 & 0.31 & 0.35 & 0.39 \\
\cline { 2 - 8 } & COV (\%) & 40 & 17 & 7 & 9 & 9 & 8 \\
\hline
\end{tabular}

As shown in Figure 9, the statistical distributions of the water contents at equilibrium can be adequately modeled by normal probability density functions. The parameter values of the normal probability density functions determined through regression analysis are given in Table 5.

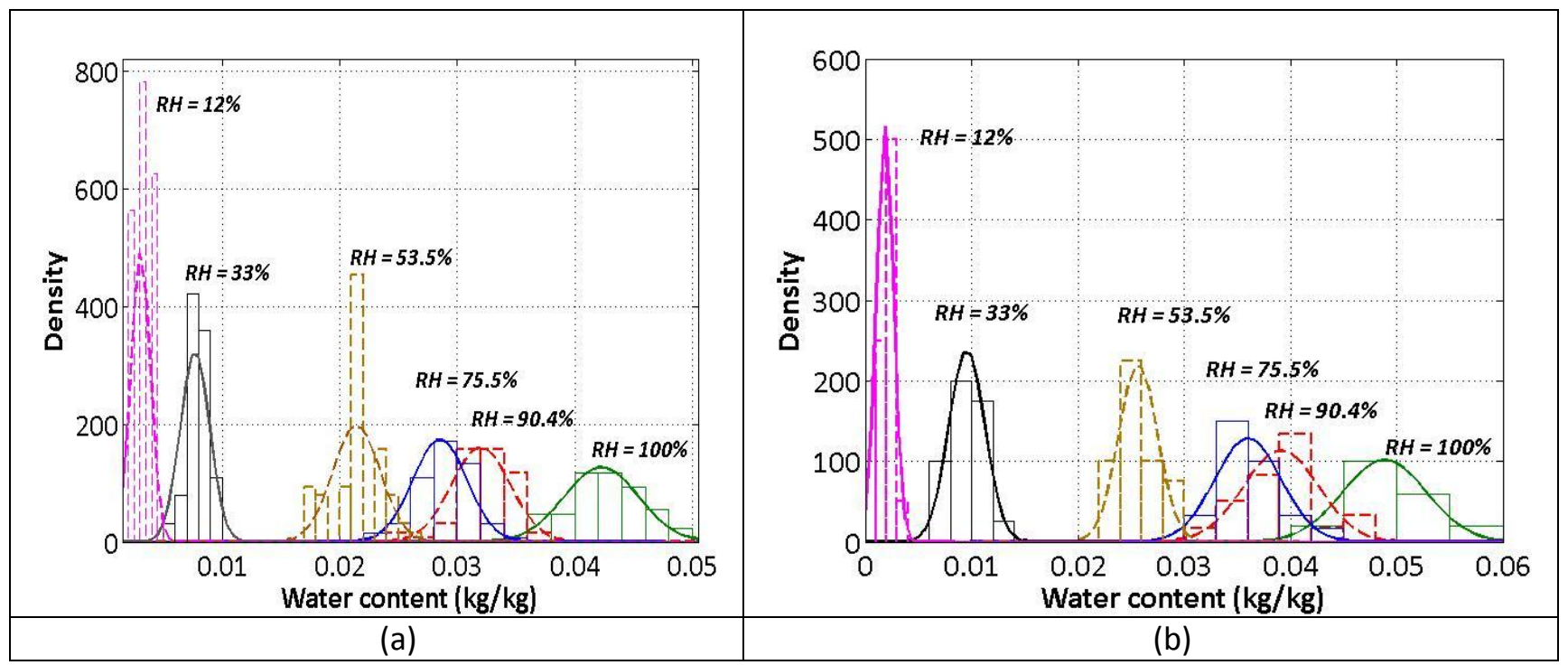

Figure 9 - Statistical distribution of water contents at equilibrium for A1 (a) and A2-1 concretes. 


\subsection{Carbonation}

The carbonation tests were performed at the CERIB and at the LaSIE (University of La Rochelle). For more details, the reader is referred to

237 [15]. From each construction site (A1 and A2), cylindrical specimens, $113 \mathrm{~mm}$ in diameter and 226mm in height were sampled from different batches. On site A1, 1 specimen per batch was sampled from the last 10 batches. On site A2, 3 specimens per batch were taken from 40 subsequent batches. After water curing during at least 28 days, each specimen was sawn at mid-height in order to obtain a disc, $113 \mathrm{~mm}$ in diameter and 50mm in height.

The protocol of the accelerated carbonation test is described in the French Standard XP P18-458. Concrete discs were first oven-dried at $45 \pm$ $5^{\circ} \mathrm{C}$ during 14 days. After this treatment, the lateral side of the disks was covered by adhesive aluminum in order to ensure an axial $\mathrm{CO}_{2}$ diffusion during the carbonation test. The discs were then placed in a chamber containing $50 \pm 5 \% \mathrm{CO}_{2}$ at $20 \pm 2^{\circ} \mathrm{C}$ and $65 \% \mathrm{RH}$. After 28 days in this environment, the concrete discs were split into two parts. $\mathrm{A} \mathrm{pH}$ indicator solution, i.e. phenolphthalein, was sprayed on the obtained cross sections in order to determine carbonation depth. The reported carbonation depth is the mean value of 24 measured depths per disc. of $A 2$ concretes. This can be attributed to the difference in binder type used in the concrete mixtures: slag substitution is known to enhance carbonation [16, 17]. A significant difference can also be observed between the two mixtures from construction site A2. This difference might be explained by a higher connectivity of the porous structure induced by the air-entraining effect of the plasticizer used for the second mixture A2- 


\begin{tabular}{|c|c|c|c|c|}
\hline Carbonation depth & $\mathrm{A} 1$ & $\mathrm{~A} 2-1$ & $\mathrm{~A} 2-2$ & $\mathrm{~A} 2$ \\
\hline Mean value $(\mathrm{mm})$ & 4.3 & 7.6 & 12.6 & 10.1 \\
\hline Standard deviation $(\mathrm{mm})$ & 1.6 & 2.6 & 1.5 & 3.3 \\
\hline COV & $37 \%$ & $35 \%$ & $12 \%$ & $33 \%$ \\
\hline
\end{tabular}

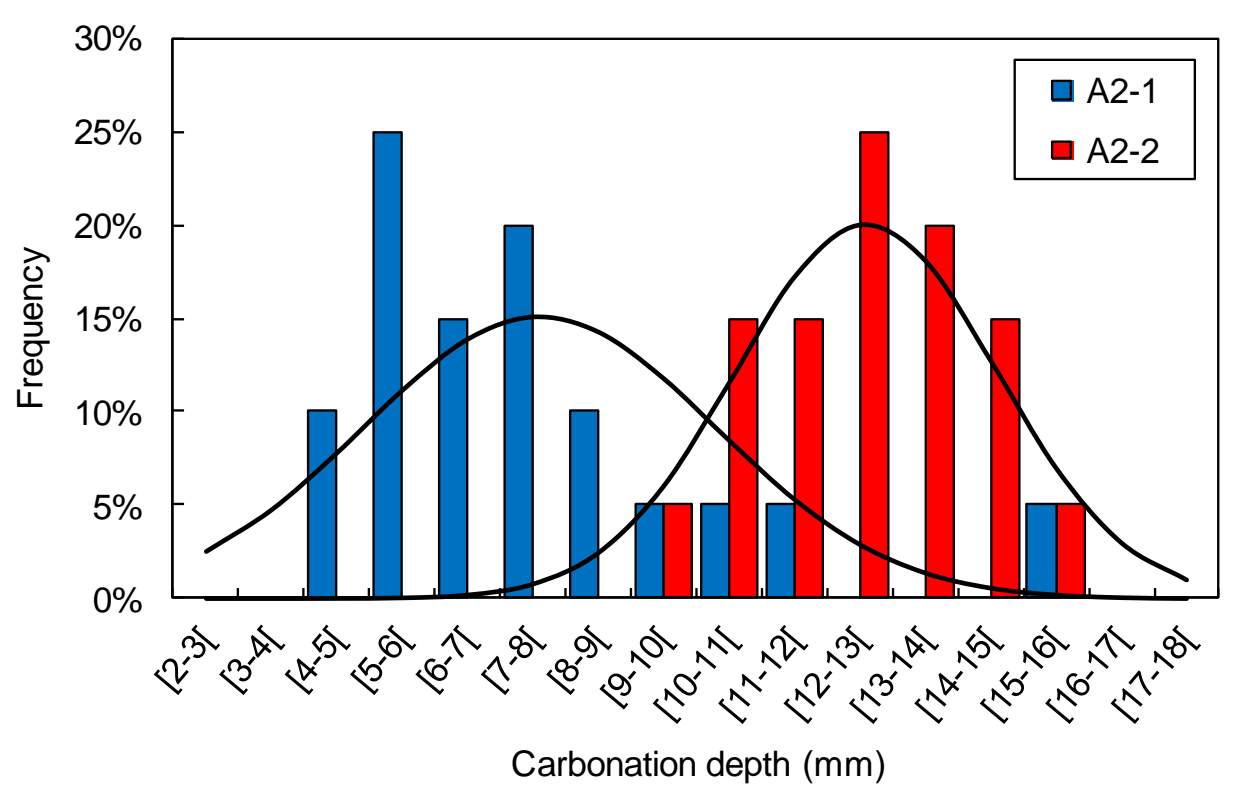




\subsection{Electrical resistivity}

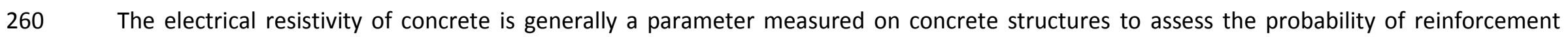

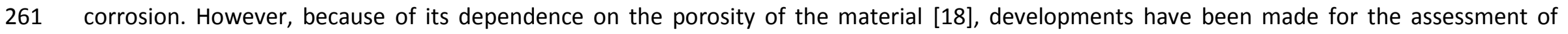
concrete transfer properties [19-21]. It appears increasingly as a durability indicator [18, 22].

The investigations done within the APPLET program, aim at assessing the reliability of resistivity measurements for concretes properties, by performing tests on $113 \times 226 \mathrm{~mm}$ cylindrical specimens using the resistivity cell technique in the laboratory. It consists in introducing an electrical current of known magnitude in a concrete specimen and measuring the potential difference thus generated between two sensors on the opposite specimen faces. Preliminary investigations have been done to study the influence of conditioning parameters on electrical resistivity measurements. Finally, a light process has been defined to store specimens before resistivity measurement in the laboratory [23].

The measurements have been performed at I2M in University Bordeaux1 (specimens having an age of 3 months, after continuous submersion in water) and at LMT (specimens of 1 year, after continuous submersion in a saturated lime solution), according to a protocol defined to distinguish different levels of variability [23]. The repeatability and reproducibility of laboratory measurement have been evaluated for each specimen; the variability of the material within a batch ( 2 batches consisting of 20 specimens each are studied), and the variability of the material during a year of casting ( 2 formulations studied from 40 specimens of test) are determined. concrete, and between 282 and $431 \Omega \mathrm{m}$ for 1 year-old concrete. This difference can essentially be attributed to the ageing, as was already observed on concretes containing fly ash [24]. 


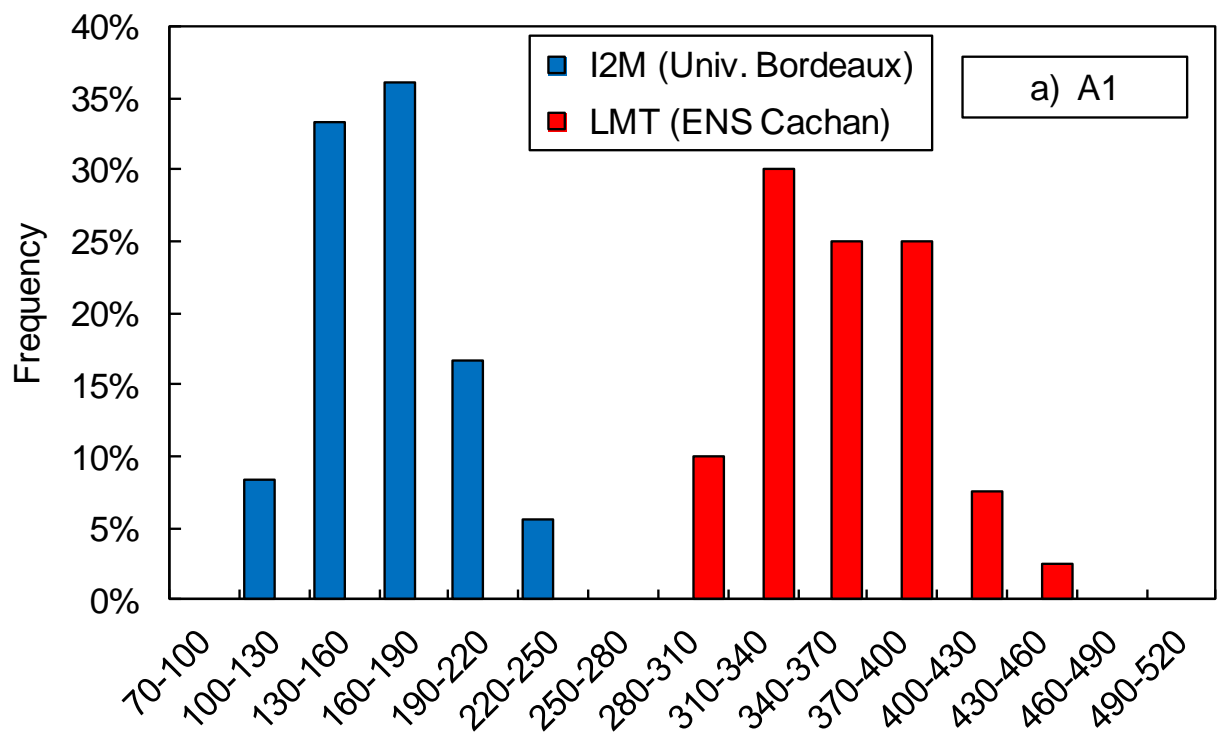

Resistivity $(\Omega \cdot m)$

Figure 11 - Resistivity distribution for concrete A1 (the specimens used at I2M were 90 days old whereas the age was 1 year at LMT). 


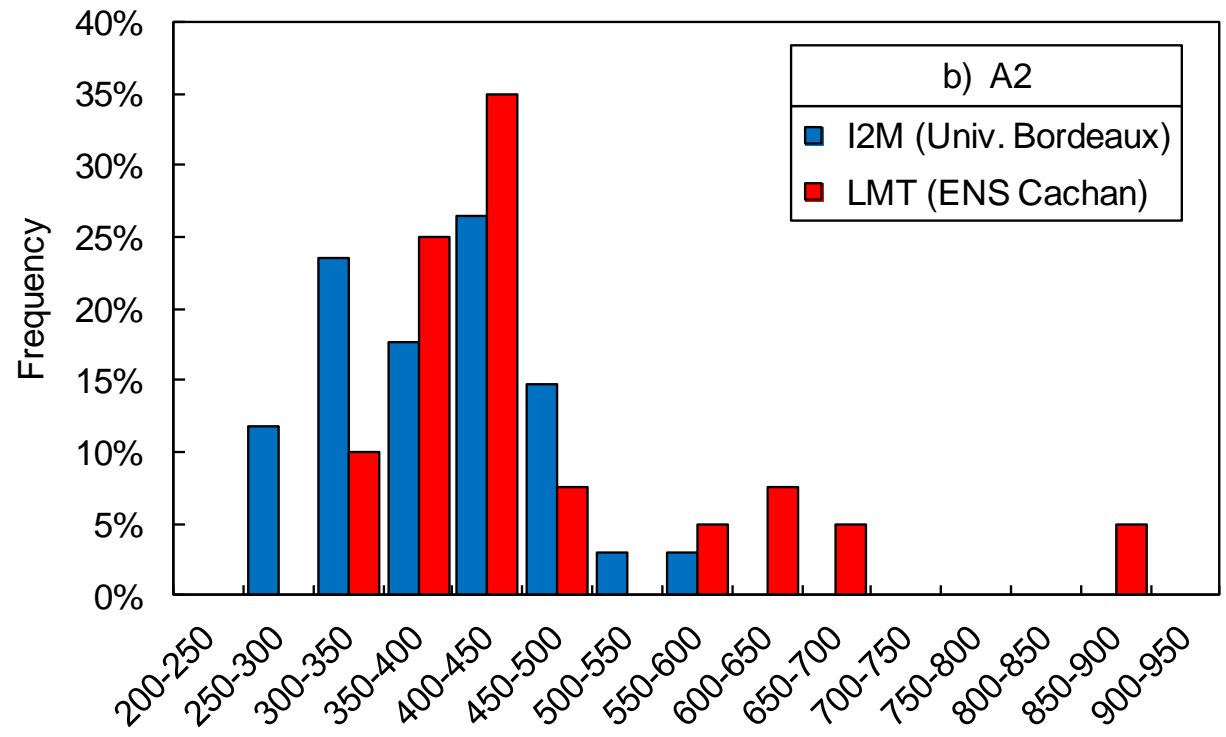

Resistivity $(\Omega \cdot m)$

Figure 12 - Resistivity distribution for concrete A2 (the specimens used at I2M were 90 days old whereas the age was 1 year at LMT).

Concrete A2 (Figure 12) does not present this difference despite the age difference and although the cement contains a significant amount of slag. It is noted that both databases express a similar behavior even if measurements on 1 year old concrete show an expected light increase in resistivity. However, for the distribution tail (towards the high resistivity values) the measured values range from 266 to $570 \Omega \mathrm{m}$ at an age of 90 days, and from 324 to $898 \Omega m$ at an age of 1 year. These results show the difficulty to compare concretes using their resistivity values. Electrical resistivity is a parameter which is very much influenced by the conditions during measurements (saturation degree of the specimen, temperature, the nature of the saturation fluid). An overview of the variability assessment for both concretes is given in Table 7. 
Table 7 - Electrical resistivity $(\Omega \mathrm{m})$ : variability observed in laboratory.

\begin{tabular}{|c|c|c|c|c|c|}
\hline \multicolumn{2}{|l|}{ Organism/Laboratory } & $12 \mathrm{M}$ & LMT & $12 \mathrm{M}$ & LMT \\
\hline \multicolumn{2}{|l|}{ Concrete } & A1 & A1 & $\mathrm{A} 2$ & $\mathrm{~A} 2$ \\
\hline \multicolumn{2}{|l|}{ Device used } & Resistivity cell & Resistivity cell & Resistivity cell & Resistivity cell \\
\hline Mean value & & 166.8 & 352.5 & 391.2 & 461.7 \\
\hline Mean repeatability & $r$ & 0.005 & - & 0.007 & - \\
\hline Mean reproducibility & $\mathrm{R}$ & 0.015 & 0.006 & 0.012 & 0.007 \\
\hline Variability within a batch $*$ & $\mathrm{Vb}$ & 0.023 & 0.076 & 0.036 & 0.035 \\
\hline Variability between batches & VB & 0.176 & 0.114 & 0.182 & 0.296 \\
\hline \multicolumn{2}{|l|}{ Age at measurements } & 90 days & 1 year & 90 days & 1 year \\
\hline
\end{tabular}

291

\section{Variability linked to measurements is the repeatability (which characterizes the equipment), and the reproducibility (which also estimates the} noise due to the protocol). Whatever the concrete and laboratory are, it is concluded that these variabilities are good. They are indeed less than $2 \%$ and underline that in laboratory the measurement results are accurate. The variability within a batch (Vb) is generally less than $5 \%(e x c e p t$ for one year old concrete A1 which remains however less than $8 \%$ ). The variability between batches (VB) is determined to be less than $20 \%$ (except for the one year old concrete A2 which reaches $29.6 \%$, but this can be explained by the modification of the mix design during the construction period).

Whatever the laboratory or the set of specimens considered, the variability is always ranked consistently: $r<R<V b<V B$. The values of $r$ and $R$ being low, variability $\mathrm{Vb}$ and $\mathrm{VB}$ are therefore only representative of the material variability. So, it is surprising to observe relatively large range, for materials the engineer considers to be homogeneous and identical. These measurements show: (1) within a batch there are significant differences between specimens; (2) for a single concrete cast regularly during one year, variability is less than $20 \%$. 

controlled conditions, regardless of the type of the specimen, should be considered. Any change in the conditioning (for instance temperature, saturation or age) influences the resistivity values measured. slightly higher than for the laboratory measurements (4.8\%).

These results illustrate that the conditions of on-site measurements are less controlled. Even though this study is not sufficient to link the techniques are consistent [23].

\subsection{Porosity}

\subsubsection{Experimental setup} different concrete mixes were studied ( 20 weeks for the first mix, then 20 weeks for the second), the specimens are denoted A2-y-x, where $y$ is the mix number ( 1 or 2 ) and $x$ the batch number (specimen numbers range from A2-1-1 to A2-1-20, then A2-2-21 to A2-2-40). The determination of porosity is studied through cylindrical specimens (diameter: $113 \mathrm{~mm}$ - height: about $50 \mathrm{~mm}$ ) sawn from the bottom part of the bigger the batch number (one batch per week); that is to say the 'temporal variability' of a given concrete. 

A2-1-1 are cast. The porosity is determined on small cylindrical specimens (diameter: $37 \mathrm{~mm}$ - height: about $74 \mathrm{~mm}$ ) cored from those cylindrical moulded specimens. A total of 39 specimens are cored from batch A1-13, and 6 from batch A2-1-1. This study was performed in the LML (Lille 1 University).

Such small diameter $(37 \mathrm{~mm})$ or small height $(50 \mathrm{~mm})$ was chosen to limit the duration of the drying process and the needed time for the experimentation. The specimens, until testing, were always kept immersed in lime saturated water at $20 \pm 2^{\circ} \mathrm{C}$ for at least 6 months $(12$ months for specimens used for temporal variability) to ensure a sufficient maturity and a very limited evolution of the microstructure. These storage conditions tend also to saturate the porous network of the material. hours and then to place the specimens under water (with the same underpressure) for 20 hours. Tests conducted at LMT highlight that for such specimens kept under water during a long period, the effect of low underpressure ( 25 millibars) on water saturation will be negligible on water saturation. Therefore, specimens used by LMT were only saturated during the immersion in lime-saturated water. by increasing the saturation time with underpressure. Specimens were placed in a hermetically closed box with a slight underpressure of 300 millibars and achievement of the saturation is assumed to be achieved when the mass variation is less than $0.1 \%$ per week. In both cases, the mass change due to this saturation under vacuum is negligible (mass change in 3 weeks amounts to only $0.15 \%$ ), and considering specimens to be completely water saturated after at least 6 months of continuous immersion appears to be valid. This mass at saturation is noted $m_{\text {sat }}$. Then, the volume of the specimens is determined through a hydrostatic weighing (mass $m_{\text {hydro }}$ ). 

called 'temporal variability' are dried in an oven at $105^{\circ} \mathrm{C}$ until mass equilibrium as recommended in the AFPC-AFREM protocol [25]. The protocol is adapted for $L M L$ tests. The drying is conducted at $60^{\circ} \mathrm{C}$ until equilibrium, then the temperature is increased to $90^{\circ} \mathrm{C}$ and then to $105^{\circ} \mathrm{C}$ to study

341 the temperature $T$ is called $\phi(T)$ and can be determined as follows (equation 3).

$$
\phi(T)=\frac{m_{\text {sat }}-m_{\text {oven }-T}}{m_{\text {sat }}-m_{\text {hydro }}}
$$

\subsubsection{Results}

Figure 13 presents the distribution of porosity for the 40 specimens (directly dried at $105^{\circ} \mathrm{C}$ ) received from the $\mathrm{A} 1$ construction site, from batch 1 to 40. This allows studying 'temporal variability' of the same concrete mix for several batches. In the same way, Figure 14 shows the distribution of porosity for the A2-1 mix (batch 1 to 20 ) and Figure 15 for the A2-2 mix (batch 21 to 40 ), measured by direct drying at $105^{\circ} \mathrm{C}$. The average porosity, standard deviation and coefficient of variation are recapitulated in Table 8.

The porosity of A1 concrete is lower than for A2 concretes, as the composition and designed strengths are clearly different. The coefficient of

351 variation for A1 and A2-1 mixes appears to be two times higher than for A2-2 (7.92\% and 9\% versus 3.96\%). This could be partly explained by the low sensitivity of the A2-2 concrete to the small changes in composition (due to the gap between theoretical and real formulation). 

presents the distribution of porosity on the 39 specimens from the batch $\mathrm{A} 1-13$ dried at $60^{\circ} \mathrm{C}$ (Figure $16 \mathrm{a}$ ), then $90^{\circ} \mathrm{C}$ (Figure $16 \mathrm{~b}$ ) and finally $105^{\circ} \mathrm{C}$ (Figure 16c) from the batch A1-13. The values of average porosity, standard deviation, coefficient of variation and minimum and maximum values are summed up in Table 9 . The effect of temperature on porosity is clearly seen with an increase of the measured porosity from $10.1 \%$ to

$35711.5 \%$ between 60 and $105^{\circ} \mathrm{C}$, but the statistical dispersion remains identical for the 3 tested temperatures. The role of drying temperature on statistical dispersion is, as a consequence, negligible. Table 10 is the analogue of Table 9 but now for the 6 specimens from the A2-1-1 batch. The same tendency is confirmed for specimens from the A2-1-1 batch, even if variability is lower (3.5\% versus $6.44 \%$ at $\left.60^{\circ} \mathrm{C}\right)$. This could be attributed to a lower material variability.

361 Eventually, a last comparison between the protocol of LMT (direct drying at $105^{\circ} \mathrm{C}$ ) and $\mathrm{LML}$ (stepwise drying at $105^{\circ} \mathrm{C}$ ) can be made regarding the porosity of A1-13 batch. It appears that the measured porosity is not the same ( $12.4 \%$ by LMT on 1 specimen, average of $11.5 \%$ by LML on 39 specimens). However, as the values of porosity on the 39 specimens range from 9.7 to $13.6 \%$, it cannot be concluded that porosity is actually different. Moreover, additional tests have been performed at the $\mathrm{LML}$ to check the effect on porosity of stepwise or direct drying at $105^{\circ} \mathrm{C}$. characterization of porosity and its variability, provided that the drying method is clearly mentioned. 


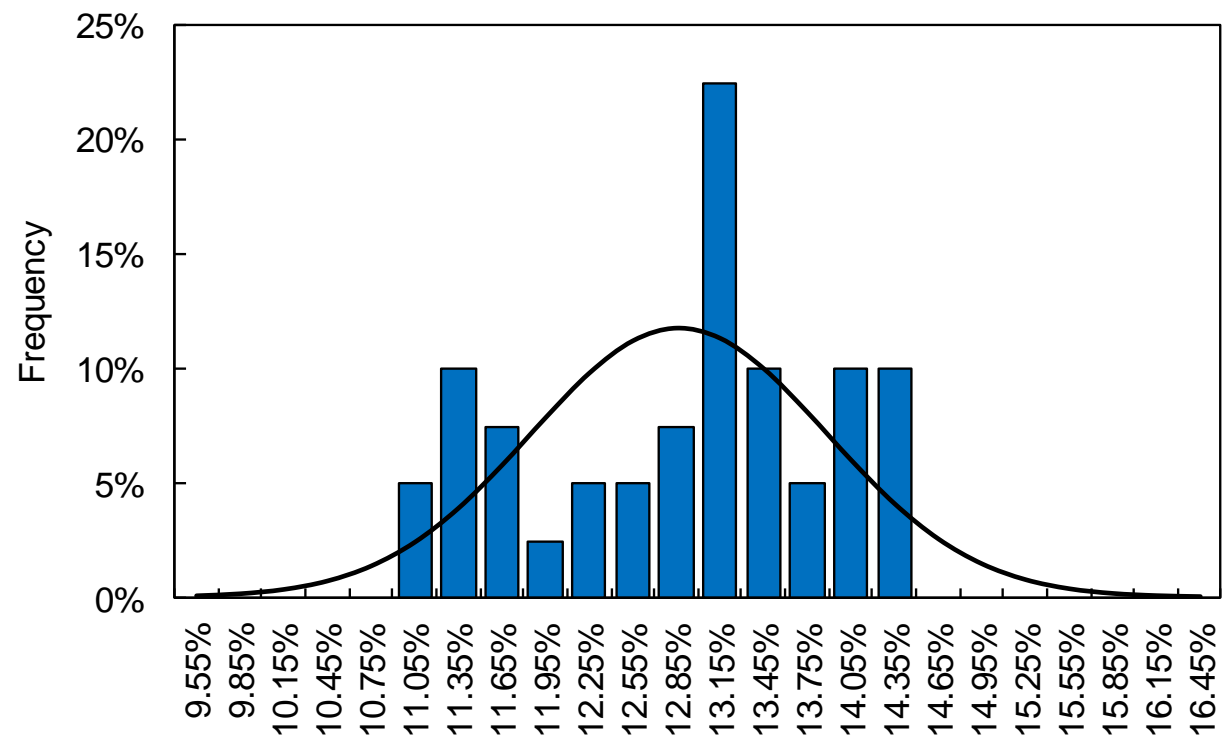

Porosity density function. Note that in this case, the normal probability density function does not fit well the results. 


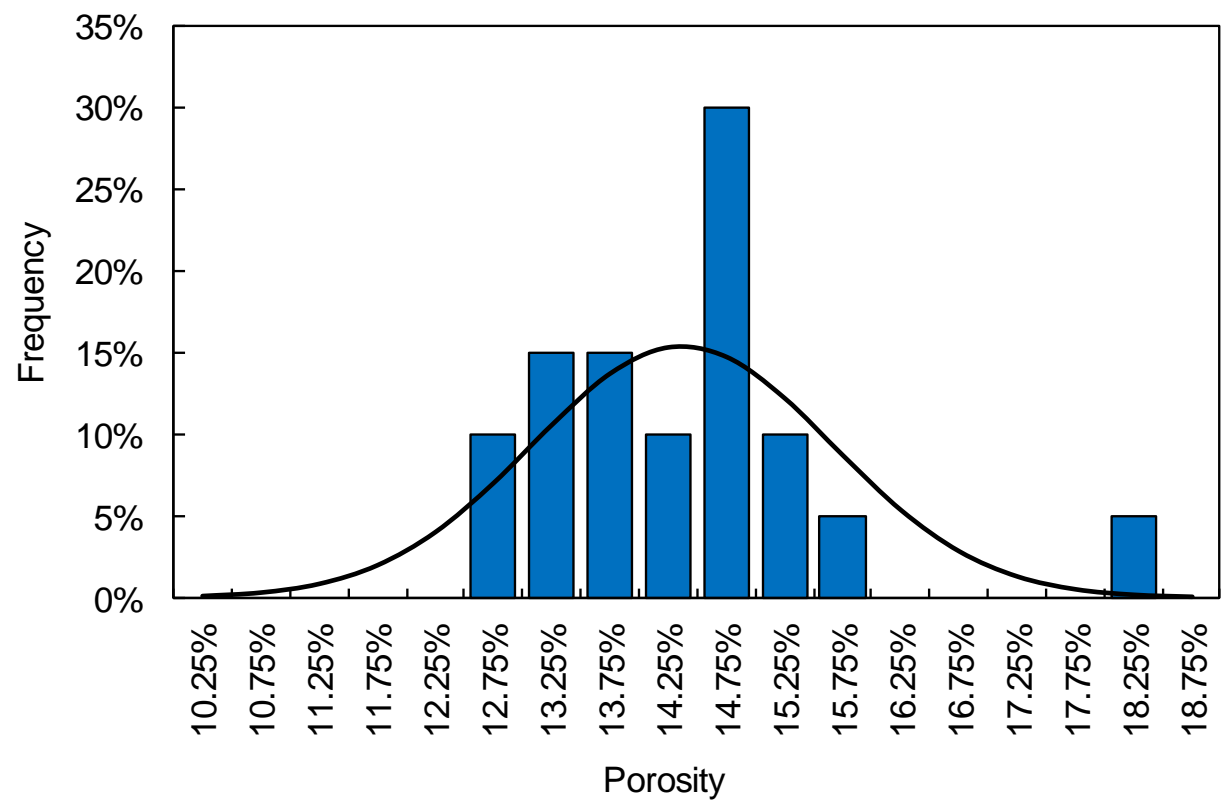




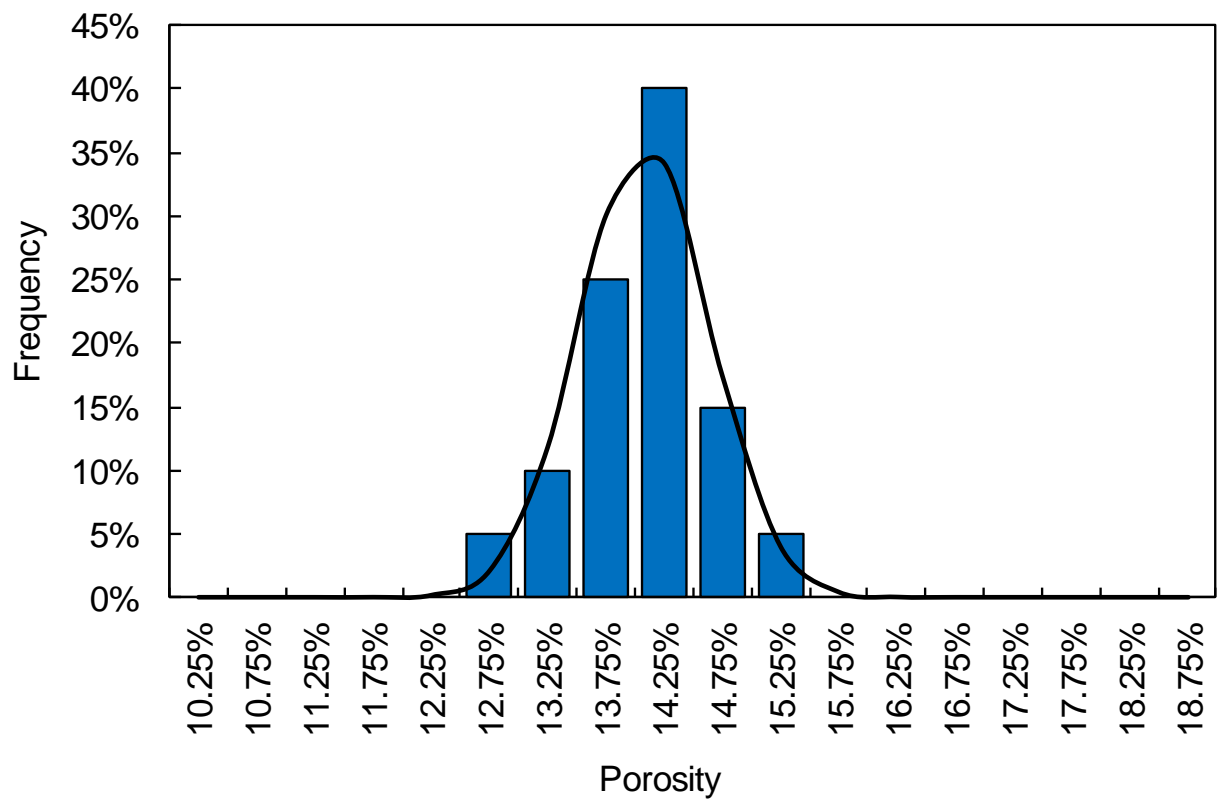

Figure 15 - Porosity distribution of A2-2 specimens (from batch 21 to 40 ) immediately dried at $105^{\circ} \mathrm{C}$. The line is the fitted normal probability density function.

379

380

Table 8 - Statistical data on porosity versus concrete mix.

\begin{tabular}{|c|c|c|c|}
\hline Concrete mix & A1 & A2-1 & A2-2 \\
\hline Average & $12.9 \%$ & $14.4 \%$ & $14.1 \%$ \\
\hline Standard deviation & $1.02 \%$ & $1.29 \%$ & $0.56 \%$ \\
\hline Coefficient of variation & $7.92 \%$ & $9.00 \%$ & $3.96 \%$ \\
\hline Minimum & $11.1 \%$ & $12.7 \%$ & $12.9 \%$ \\
\hline Maximum & $14.4 \%$ & $18.2 \%$ & $15 \%$ \\
\hline
\end{tabular}

Table 9 - Statistical data on porosity versus drying temperature (39 specimens of batch A1-13).

\begin{tabular}{|c|c|c|c|}
\hline Drying temperature & $60^{\circ} \mathrm{C}$ & $90^{\circ} \mathrm{C}$ & $105^{\circ} \mathrm{C}$ \\
\hline Average & $10.1 \%$ & $10.9 \%$ & $11.5 \%$ \\
\hline Standard deviation & $0.65 \%$ & $0.69 \%$ & $0.75 \%$ \\
\hline
\end{tabular}




\begin{tabular}{|c|c|c|c|}
\hline Coefficient of variation & $6.44 \%$ & $6.35 \%$ & $6.49 \%$ \\
\hline Minimum & $8.5 \%$ & $9.2 \%$ & $9.7 \%$ \\
\hline Maximum & $11.8 \%$ & $12.8 \%$ & $13.6 \%$ \\
\hline
\end{tabular}

384

385

386

387
Table 10 - Statistical data on porosity versus drying temperature (6 specimens of batch A2-1).

\begin{tabular}{|c|c|c|c|}
\hline Drying temperature & $60^{\circ} \mathrm{C}$ & $90^{\circ} \mathrm{C}$ & $105^{\circ} \mathrm{C}$ \\
\hline Average & $12.1 \%$ & $12.9 \%$ & $13.4 \%$ \\
\hline Standard deviation & $0.43 \%$ & $0.46 \%$ & $0.47 \%$ \\
\hline Coefficient of variation & $3.50 \%$ & $3.57 \%$ & $3.54 \%$ \\
\hline
\end{tabular}

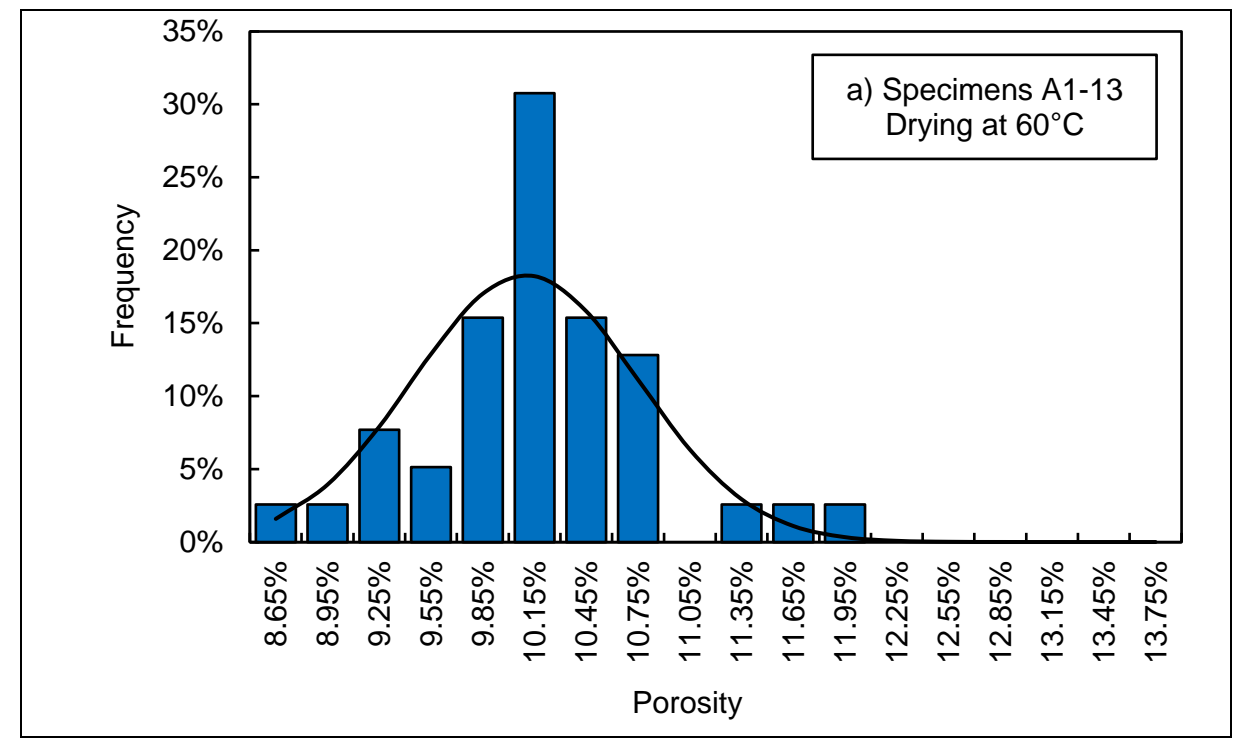



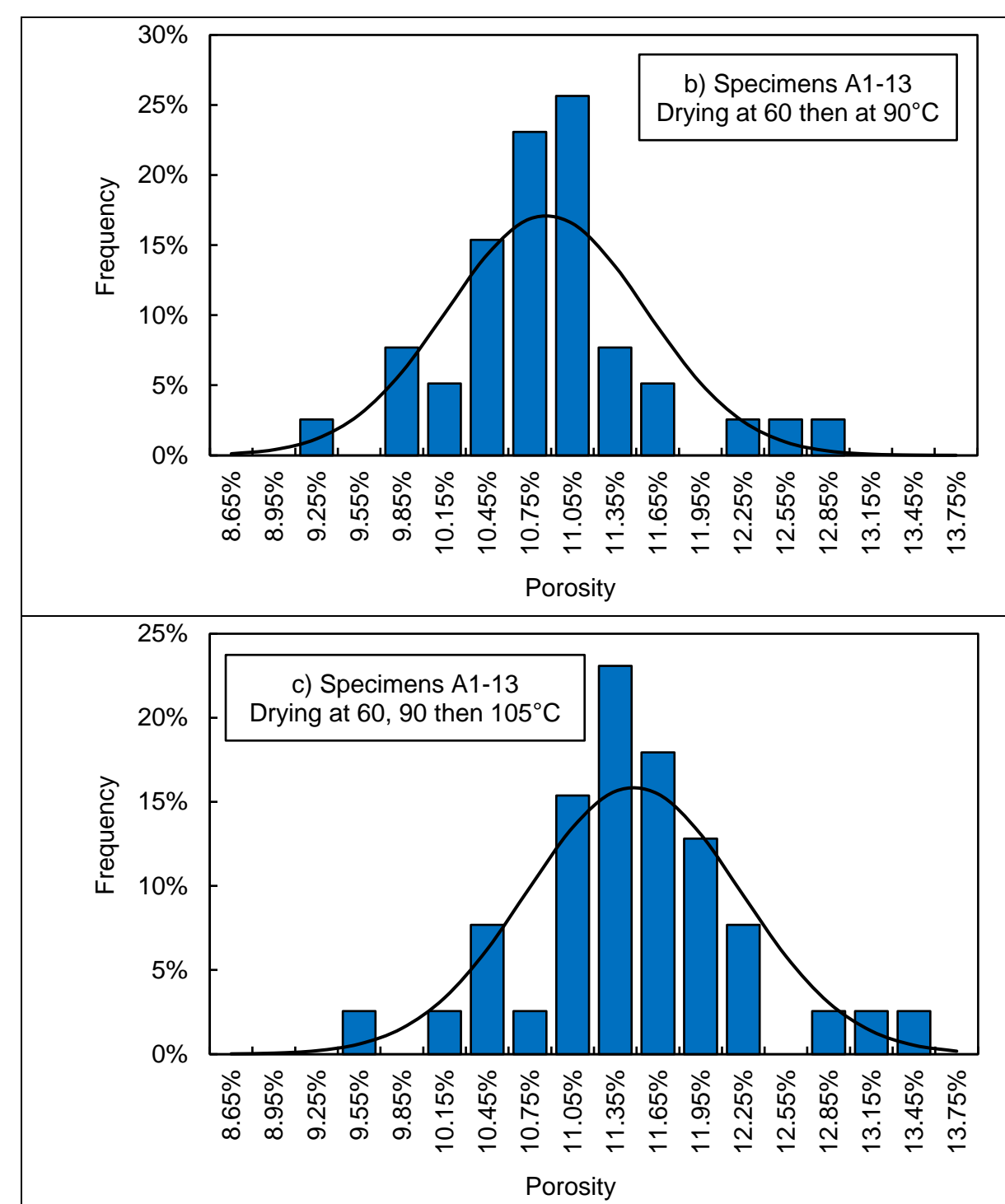
density function. 


\subsection{Leaching}

The characterization of concrete variability in relation to leaching was performed at LMT and will be described in the following section. Other complementary experiments were also conducted simultaneously at CEA to check the influence of temperature and tests conditions. These tests are not described in this article. For more details, the reader is referred to $[27,28]$.

The measurements performed in LMT within the APPLET project are accelerated tests using ammonium nitrate solution [29]. After a storage of about one year in lime saturated water, the specimens are immersed in a $6 \mathrm{~mol} / \mathrm{L}$ concentrated $\mathrm{NH}_{4} \mathrm{NO}_{3}$ solution. The specimens are immersed in the ammonium nitrate solution 8 by 8 , every 8 weeks. For security reasons, the containers with the aggressive solution and the specimens are kept outside the laboratory, and thus subjected to temperature variations. Therefore, a pH and temperature probe is placed in the container, so as to register once an hour the $\mathrm{pH}$ and temperature values in the ammonium nitrate solution. If the $\mathrm{pH}$ of the solution reaches the threshold value of 8.8 , the ammonium nitrate solution of the container is renewed.

Before immersion in the ammonium nitrate solution, the specimens had been sandblasted to remove a thin layer of calcite formed on the specimen surface during the storage phase, which might slow down or prevent the degradation of the specimens. The degradation depths are measured at 4 experimental terms for each specimen: 4, 8, 14 and 30 weeks. For each experimental time intervals, the specimens are taken from the containers, and a slice is sawn, on which the degradation depth is revealed with phenolphthalein. The thickness of the slice is adapted to the experimental interval (the longer the specimen has been immersed in ammonium nitrate solution, the larger the slice). The rest of the concrete specimen is then placed back in the ammonium nitrate solution container. Phenolphthalein is a pH indicator through colorimetric reaction: the sound part of the concrete has a highly basic $\mathrm{pH}$ so that the phenolphthalein turns pink, whereas the degraded area has a $\mathrm{pH}$ below the 
colorimetric threshold of the phenolphthalein, and therefore remains grey. Actually, it seems that the degradation depth revealed with phenolphthalein is not exactly the position of the portlandite dissolution front [30], but the ratio between both is not completely acknowledged; this is the reason why in this study for practical reasons the degradation depth is considered to be equal to the one revealed by phenolphthalein.

In Figure 17 one can observe the degradation depths revealed with phenolphthalein for the 4 experimental terms on the very same specimen.

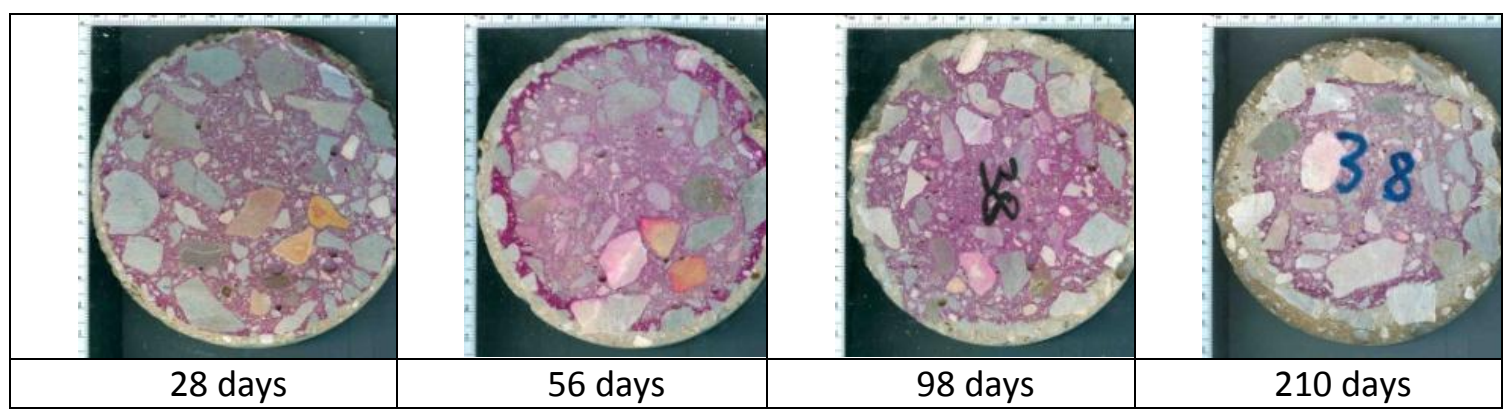

Figure 17 - Degradation depths observed on the same specimen (batch 38 of A1 concrete) at the 4 experimental time intervals of the ammonium nitrate leaching test.

For every experimental test interval, each specimen is scanned to obtain a digital image of the sawn slice of concrete after spraying with phenolphthalein. The degradation depth is then numerically evaluated over about a hundred radiuses. For these measurements, special care has been taken to avoid the influence of aggregates particles: the degradation has been measured on mortar exclusively. The average coefficient of variation of the degradation depth measured on a concrete specimen (about a hundred values) is $13 \%$ at 28 days, $12 \%$ at 56 days, $10 \%$ at 98 days and finally $8 \%$ at 210 days. This decreasing coefficient of variation is partly explainable by the fact that the radius of the sound concrete decreases with time, therefore the perimeter for the measurement of the degradation depth decreases as well. 


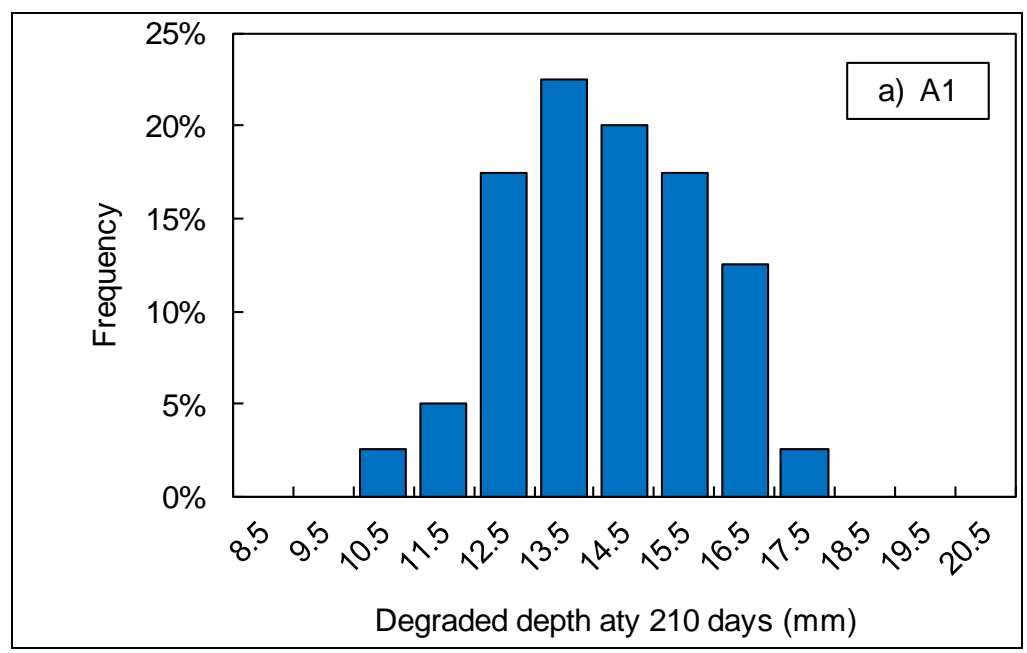




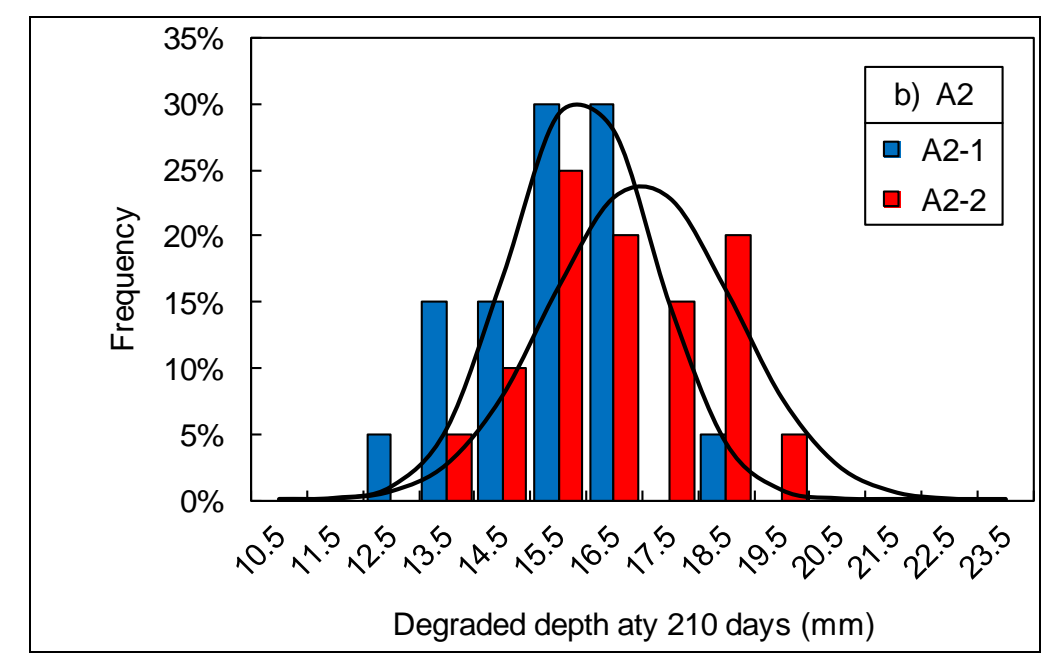

Figure 18 - Degraded depth distribution at 96 days (accelerated degradation using ammonium nitrate).

Table 11 - Degradation depths observed in the accelerated leaching test: number of specimens tested (Nb), mean value and coefficient of variation.

\begin{tabular}{|c|c|c|c|c|c|c|c|c|c|}
\hline & & \multicolumn{2}{|c|}{28 days } & \multicolumn{2}{c|}{56 days } & \multicolumn{2}{c|}{96 days } & \multicolumn{2}{c|}{210 days } \\
\hline Site & $\mathrm{Nb}$ & Mean & COV & Mean & COV & Mean & COV & Mean & COV \\
\hline A1 & 40 & 4.2 & $20.8 \%$ & 6.3 & $19.4 \%$ & 8.8 & $16.8 \%$ & 14.6 & $10.1 \%$ \\
\hline A2-1 & 20 & 4.6 & $10.9 \%$ & 7.0 & $8.1 \%$ & 9.8 & $8.0 \%$ & 15.9 & $8.1 \%$ \\
\hline A2-2 & 20 & 6.0 & $12.0 \%$ & 10.2 & $12.7 \%$ & 12.8 & $9.9 \%$ & 17.0 & $9.8 \%$ \\
\hline
\end{tabular}

In order to eliminate the influence of temperature in the interpretation of the accelerated leaching tests, so as to assess the material variability, two modelling approaches have been proposed. The first approach is a global macroscopic modelling based on the hypothesis that the leaching kinetics are proportional to the square root of time and thus that the process is thermo-activated. This means that an Arrhenius law can be applied on the slope of the linear function giving the degradation depth with regard to the square root of time (4). The basic idea of this approach is to determine, from the degradation depths measured at the four experimental intervals for every specimen, one scalar parameter 


$$
e(t, T)=k(T) \sqrt{t}=k_{0} \exp \left(-\frac{E_{A}}{R T}\right) \sqrt{t}
$$
to simulate the tests performed within the APPLET project. This approach is based on the mass balance equation for calcium (5) [32, 33], under the assumption of a local instantaneous chemical equilibrium, and combined with thermo-activation laws for the diffusion process and the local equilibrium of calcium. It appears that among the input parameters of this model, the most influential on the leaching kinetics are the porosity $\phi$ and the coefficient of tortuosity coefficient $\tau$, which is a macroscopic parameter to model the influence of coarse aggregates on the kinetics of diffusion through the porous material [34]. This tortuosity coefficient, although not directly measurable by experiments, is nevertheless identifiable by inverse analysis. The main difference between $\tau$ and the parameter $k_{0}$ of the global thermo-activation of the leaching process is that $\tau$ is by definition independent from both temperature and porosity.

$$
\frac{\partial}{\partial t}\left(\phi C_{C a}\right)=-\operatorname{div}\left[-\tau D_{0} e^{k \phi} \operatorname{grad}\left(C_{C a}\right)\right]-\frac{\partial S_{C a}}{\partial t}
$$



parameter of the global thermo-activation of the leaching process $k_{0}$. It appears that the tortuosity is significantly lower for the first concrete formulation (site A1) slower degradation kinetics), but for the two formulations of the second site, the coefficient has exactly the same mean value, and only the variability decreases (which was the objective sought by the readjustment of the concrete formulation). This equality between the two formulations of the second construction operation could not be foreseen through the degradation depths (Table 11) or the parameter $k_{0}$ (Table 12). This difference in the mean values for $k_{0}$ (whereas the mean values for $\tau$ are identical) may be interpreted as the influence of the porosity, which is a highly important parameter on the kinetics of degradation, and that this is integrated in parameter $k_{0}$ but not in the coefficient of tortuosity coefficient $\tau$.

464

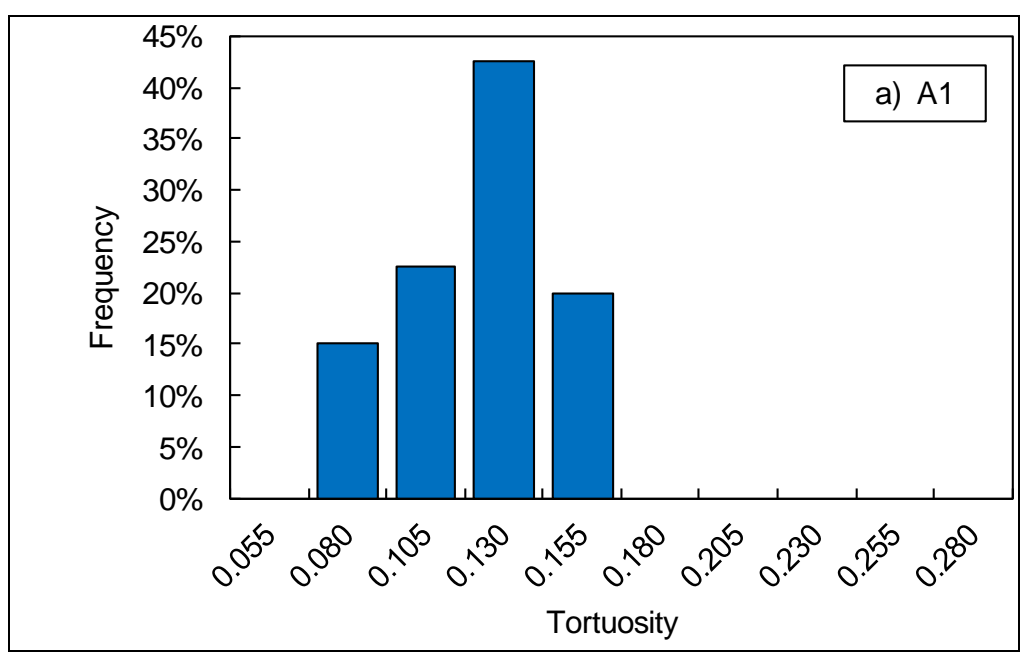




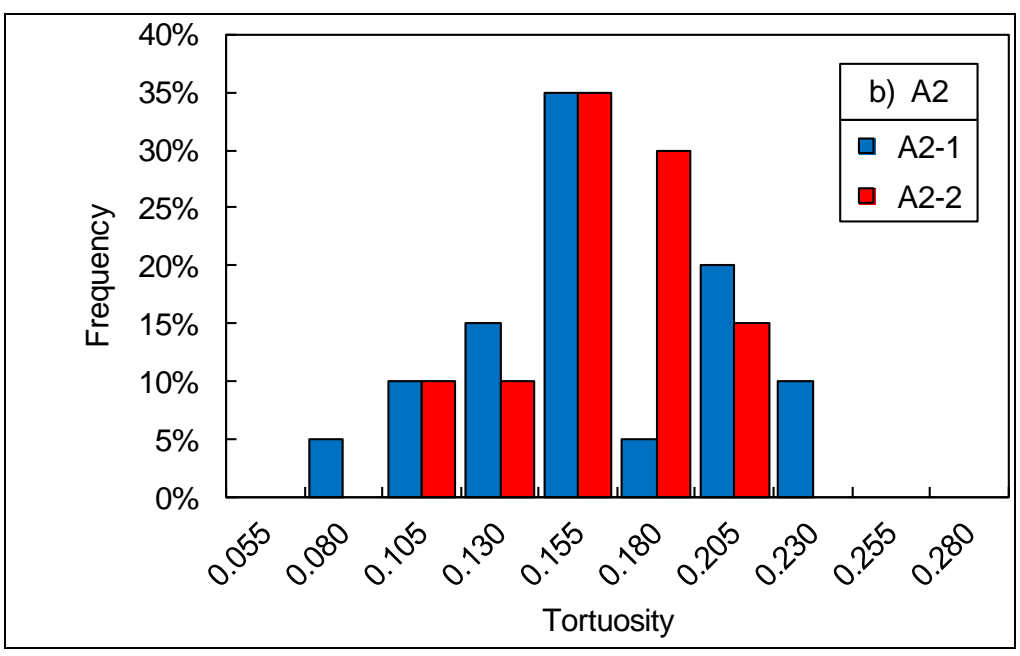

Figure 19 - Tortuosity distribution (using ammonium nitrate).

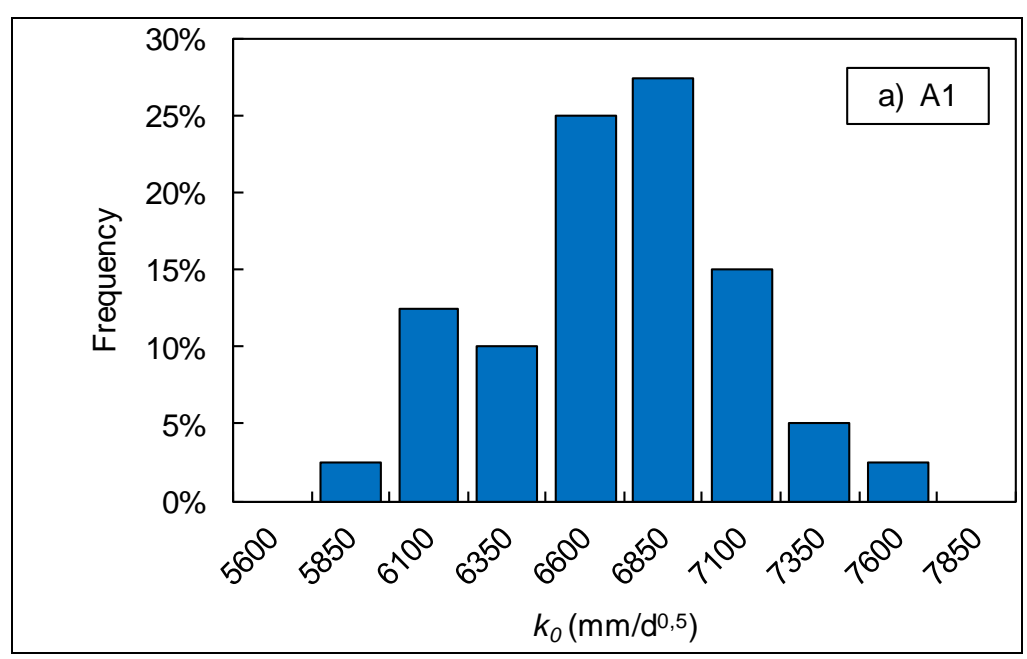




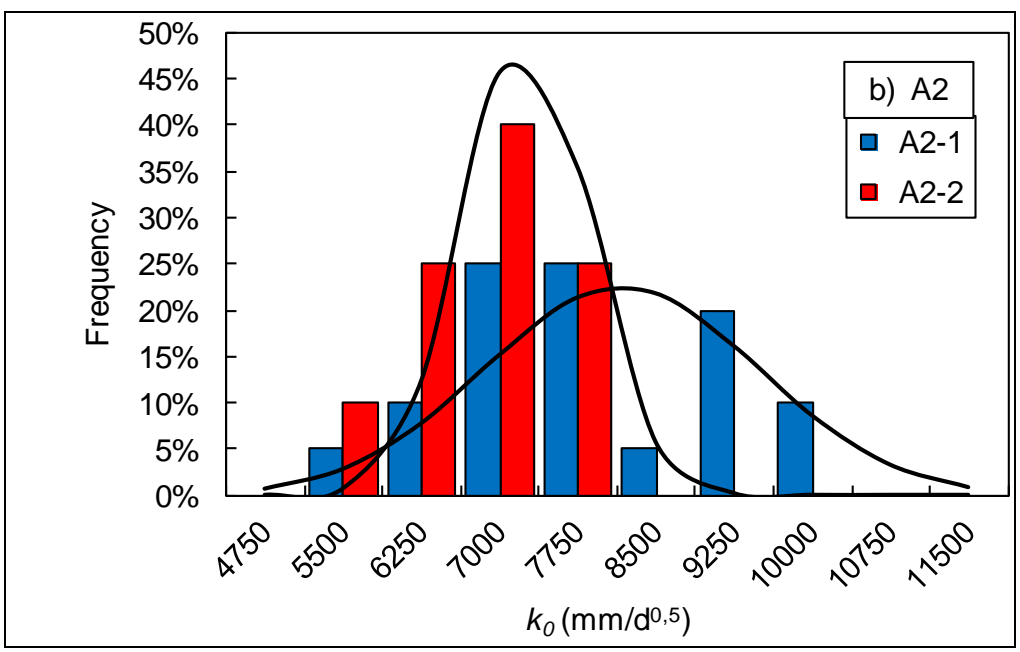

Figure 20 - Accelerated degradation kinetics distribution (using ammonium nitrate). The solid lines are guides for the eyes only (normal probability density function).

Table 12 - Measured and identified variability of the porosity $\phi$, the coefficient of tortuosity coefficient $\tau$ and the parameter $k_{0}$ of global thermo-activation of the leaching process.

\begin{tabular}{|c|c|c|c|c|c|c|c|}
\hline & & \multicolumn{2}{|c|}{ Porosity $\phi$} & \multicolumn{2}{c|}{ Tortuosity $\tau$} & \multicolumn{2}{c|}{ Kinetics $k_{0}\left[\mathrm{~mm} / \mathrm{d}^{0.5}\right]$} \\
\hline & $\mathrm{Nb}$ & Average & COV & Average & COV & Average & COV \\
\hline A1 & 40 & $12.9 \%$ & $7.9 \%$ & 0.134 & $15.1 \%$ & 6.82 & $5.6 \%$ \\
\hline A2-1 & 20 & $14.4 \%$ & $9.0 \%$ & 0.173 & $24.5 \%$ & 8.17 & $16.2 \%$ \\
\hline A2-2 & 20 & $14.1 \%$ & $4.0 \%$ & 0.173 & $17.5 \%$ & 7.25 & $8.3 \%$ \\
\hline
\end{tabular}

\subsection{Permeability}

The gas permeability of the concrete produced at the first construction site (A1 site) was characterized at CEA using a Hassler cell: this is a constant head permeameter which is very similar to the well-known Cembureau device [35]. The specimens to be used with this device are cylindrical with a diameter equal to $40 \mathrm{~mm}$, and their height can range from a few centimeters up to about ten. The device can be used to apply 


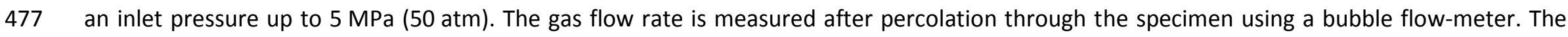

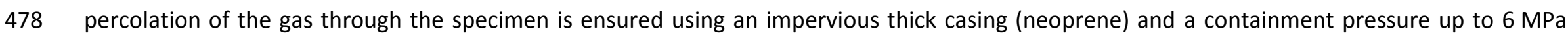

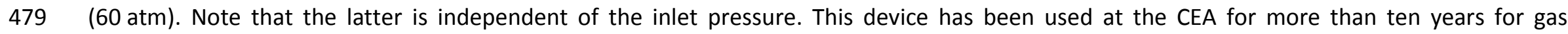

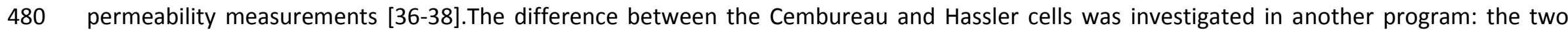

481

482

483 484

485

486 487 488 apparatus showed very similar results [39].

The specimens to be tested $(\varnothing 40 \mathrm{~mm})$ were obtained by coring the large specimens $(\varnothing 113 \times 226 \mathrm{~mm})$ cast at the first construction site (A1). Both ends of each cored specimen $(\varnothing 40 \times 226 \mathrm{~mm})$ were sawn off and discarded. The remaining part was then cut to yield three specimens $(\varnothing 40 \times 60 \mathrm{~mm}$, cf. Figure 21). A maximal number of nine specimens could be obtained from each $\varnothing 113 \mathrm{~mm}$ specimen. According to our experience in concrete permeability measurements, these dimensions $(\varnothing 40 \times 60 \mathrm{~mm})$ are sufficient to ensure representative and homogeneous results. Note that the large specimens $(\varnothing 113 \times 226 \mathrm{~mm})$ were kept under water (with lime at $\left.20^{\circ} \mathrm{C}\right)$ for eleven months before use as to ensure optimal hydration and prevent carbonation. 

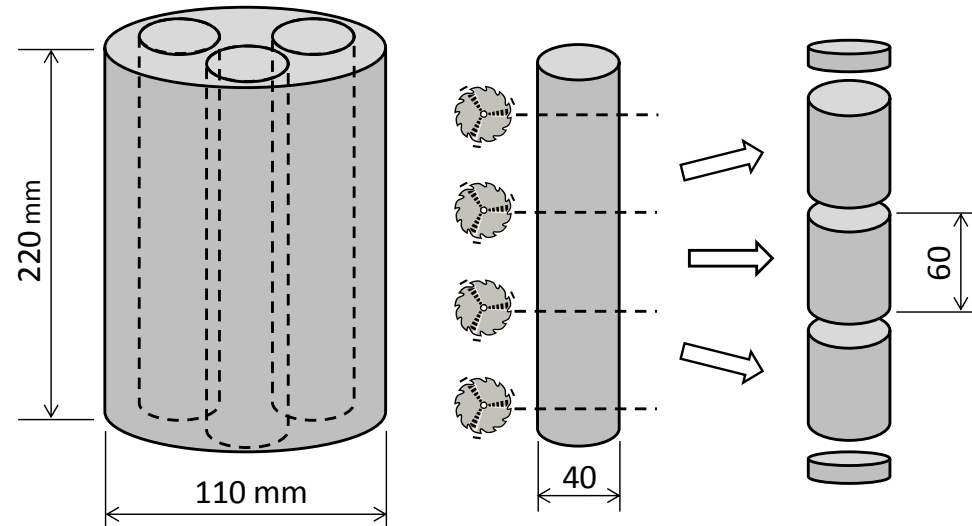

Before the permeability characterization, the specimens were completely dried at $105^{\circ} \mathrm{C}$ (that is to say until constant weight) according to the recommendations $[25,35]$. This pre-treatment is known to induce degradation of the hardened cement paste hydrates. Yet it appeared as the best compromise between representativeness, drying complexity and duration. From a practical point of view, the complete drying was achieved in less than one month. After the drying, the specimens were let to cool down in an air-conditioned room at $20^{\circ} \mathrm{C} \pm 1^{\circ} \mathrm{C}$ in a desiccator above silica gel (in order to prevent any water ingress). which the specimens were in thermal equilibrium. The measurement of the gas flow rate at the outlet (after percolation through the specimen) and when the steady state was reached (constant flow-rate) allowed the evaluation of the effective permeability $K_{e}\left[\mathrm{~m}^{2}\right][40]$. The intrinsic permeability was then estimated using the approach proposed by Klinkenberg [40,41]. The latter allows the estimation of the impact of the gas 

permeability $K\left[\mathrm{~m}^{2}\right]$ and the inverse of the test average pressure $\bar{P}[\mathrm{~Pa}]$ :

503

505 study. 


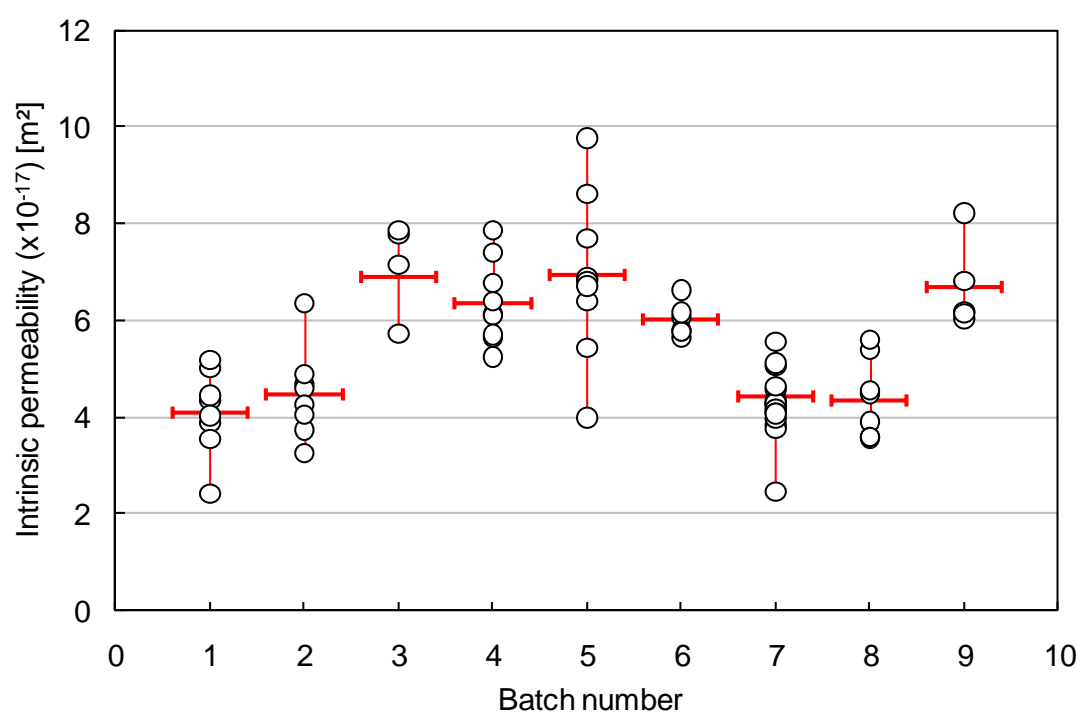

Figure 21 - Intrinsic permeability (using nitrogen) of the first nine batches (construction site A1). Each circle corresponds to an experimental value obtained using a cored specimen. The horizontal bar stands for the mean value for each batch.

The results emphasize the important variability which can be encountered within a $\varnothing 113 \mathrm{~mm}$ specimen: for instance for batch 5 , the permeability was found to vary by a factor of 2 . This variability is very unusual with regard to our experience in permeability measurements of laboratory concretes. It is believed that the specimens manufacturing on site by the site workers in industrial conditions (time constraints, large concrete volume to be placed) did result in the decrease of the concrete placement quality compared to laboratory fabrication [42, 43]. This point was supported by the presence of large air voids (about one centimeter large) within the specimens which could be occasionally detected during the coring operations. These voids are also believed to contribute to the permeability increase [44]. 

test the specimen was removed from the permeameter, left in a desiccator for at least one day and then tested again). The measurements standard deviation was equal to $0.17 \times 10^{-17} \mathrm{~m}^{2}$ (for an average value equal to $4.1 \times 10^{-17} \mathrm{~m}^{2}$ ). The coefficient of variation is about $4 \%$, which is far less than the variability observed. For clarity, in figure 21 the uncertainty related to the test corresponds to the symbol height.

531 Simultaneously, experiments were conducted at LML: permeability was measured using cylindrical specimens (diameter: $37 \mathrm{~mm}$ - height: 532 about $74 \mathrm{~mm}$ ) cored from bigger moulded specimens of the A1 construction site (batch A1-13). The specimens, until testing, were always kept immersed in lime saturated water at $20 \pm 2^{\circ} \mathrm{C}$. Permeability was measured by gas (argon) percolation in a triaxial cell on small specimens dried in oven at $90^{\circ} \mathrm{C}$ or at 90 then at $105^{\circ} \mathrm{C}$ until mass equilibrium. The choice of argon as a percolating gas is due to its inert behavior with cement, allowing an adequate measure of the material permeability. The whole experimental permeability measurement device is composed of a triaxial cell that allows the application of a confining pressure on the specimen through oil injection. The specimen is equipped with a drainage disc (stainless steel with holes and lines ensuring a one-dimensional homogenous gas flow at the surface of the specimen) at each end. The specimen is then placed in the bottom section of the cell where the gas pressure Pi will be applied. A drainage head, to allow flowing of gas to the exterior of the cell (atmospheric pressure Pf) after the percolation through the specimen, is placed on the upper part of the specimen. Then a protective permeability cell is presented in Figure 22 . 


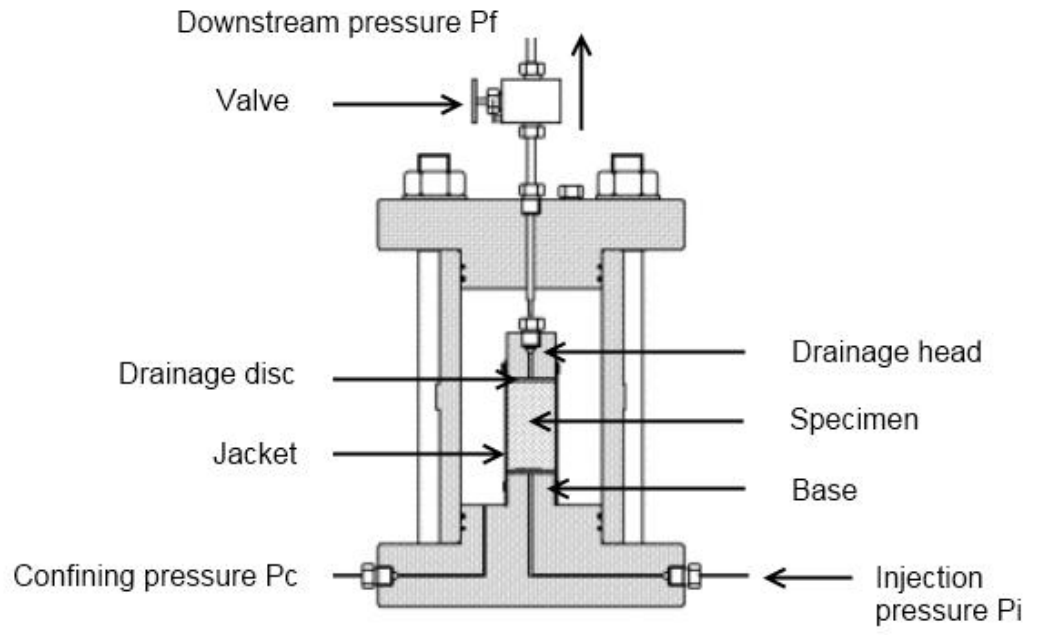

Figure 22 - Sketch of the triaxial cell for permeability measurements at LML.

The measurement procedure and determination of permeability is performed as follows. Once the specimen is in the triaxial cell, confining pressure is increased and kept constant to $4 \mathrm{MPa}$. Then, the gas is injected at a pressure of about $2 \mathrm{MPa}$, and the downstream pressure $P_{f}$ is in equilibrium with atmospheric pressure (0 MPa in relative pressure). This injection is directly done by the reducing valve of the gas bottle, which also feeds a buffer circuit. This phase is pursued until a permanent gas flow inside the specimen is achieved. This is detected by a stabilization of the injection pressure $P_{i}$. At this moment, the reducing valve is closed, and only the buffer circuit provides gas to the specimen. As a consequence, a drop of pressure appears since gas continues to flow through the specimen. The permeability is deduced from the time $\Delta t$ needed to get a given change $\Delta P$ of the injection pressure. This decrease of injection pressure should remain low to ensure the quasi-permanent flow hypothesis. The volume of the buffer circuit $V$ is known by preliminary tests, and with the perfect gas hypothesis, the effective permeability $K_{e}$ is calculated using: 


$$
K_{e}=2 \frac{\mu_{g} Q_{m} L P_{m}}{S\left(P_{m}^{2}-P_{f}^{2}\right)}
$$

557

$Q_{m}$ is the medium flow, which under isothermal conditions is:

563

$$
P_{m}=P_{i}-\frac{\Delta P}{2}
$$

where $\mu_{g}$ is the gas viscosity, $L$ the height of the specimen, $S$ its cross section and $P_{m}$ the medium pressure given by:

The measured permeability $K_{e}$ is an effective permeability (and not an intrinsic) being dependent on injection pressure due to the Klinkenberg effect. However, for an injection pressure of $2 \mathrm{MPa}$, this effect is negligible, as confirmed by additional tests. A refined description of permeability devices can be found in [45] . For our tests, $\Delta P$ is $0.025 \mathrm{MPa}$, the injection pressure varies around $2 \mathrm{MPa}$ (between 2.02 and 2.24 $\mathrm{MPa}$ ). The permeability is determined on 6 specimens from batch $\mathrm{A} 1-13$, dried at $90^{\circ} \mathrm{C}$, and values are presented in Table 13. The permeability of each specimen is measured two times to evaluate the immediate repeatability (between two measurements, the specimen remains in the cell 
571 under confining pressure, the reducing valve is opened until a permanent gas flow inside the specimen is achieved and finally the second

572 measure is performed). 3 additional specimens from the same batch are firstly dried at $90^{\circ} \mathrm{C}$ until mass equilibrium, then at $105^{\circ} \mathrm{C}$, and their

573 permeability is determined. Table 14 gives an overview of the statistical data of these specimens. The statistical dispersion, as for porosity, has

574 the same order of magnitude at both 90 and $105^{\circ} \mathrm{C}$ (around $11-12 \%$ ), and thus the effect of temperature on variability remains negligible.

575

576

Table 13 - Permeability after drying at $90^{\circ} \mathrm{C}$ (batch A1-13).

\begin{tabular}{|c|c|c|}
\hline \multirow{2}{*}{ Specimen } & \multicolumn{2}{|c|}{ Permeability $\left(\times 10^{-17} \mathrm{~m}^{2}\right)$} \\
\cline { 2 - 3 } & $1^{\text {st }}$ run & $2^{\text {nd }}$ run \\
\hline $19-3$ & 2.83 & 2.81 \\
\hline $19-5$ & 2.97 & 2.99 \\
\hline $38-2$ & 2.62 & 2.61 \\
\hline $38-3$ & 2.25 & - \\
\hline $38-4$ & 2.91 & 2.88 \\
\hline $38-5$ & 3.24 & 3.24 \\
\hline
\end{tabular}

Table 14 - Statistical data on permeability for dried specimens at $90^{\circ} \mathrm{C}$ or at 90 and then $105^{\circ} \mathrm{C}$ (batch A1-13).

\begin{tabular}{|c|c|c|c|c|}
\hline & $\begin{array}{c}\text { Specimen } \\
\text { number }\end{array}$ & $\begin{array}{c}\text { Average permeability } \\
\left(\times 10^{-17} \mathrm{~m}^{2}\right)\end{array}$ & $\begin{array}{c}\text { Standard deviation } \\
\left(\times 10^{-17} \mathrm{~m}^{2}\right)\end{array}$ & Coefficient of variation \\
\hline $90^{\circ} \mathrm{C}$ & 6 & 2.80 & 0.34 & $12.1 \%$ \\
\hline $105^{\circ} \mathrm{C}$ & 3 & 4.40 & 0.49 & $11.1 \%$ \\
\hline
\end{tabular}




\subsection{Construction sites comparison}

Table 15 summarizes all the coefficients of variation obtained for all the experiments concerning the two construction sites. The change of mix design during the production at site $A 2$ could be seen on several physical parameters, however not on the mechanical ones. If the entire

Table 15 - Coefficients of variation of all the tests.

\begin{tabular}{|c|c|c|c|c|c|}
\hline Test & Laboratory & A1 & A2/1 & A2/2 & A2 \\
\hline Compressive strength & Vinci & $7.3 \%$ & $11.1 \%$ & $11.1 \%$ & $12 \%$ \\
\hline Compressive strength & LMT & $10.5 \%$ & $11.3 \%$ & $11.1 \%$ & $12 \%$ \\
\hline Tensile strength & LMT & $13.3 \%$ & $9.7 \%$ & $9.3 \%$ & $9.9 \%$ \\
\hline Young modulus & LMT & $6.2 \%$ & $8.2 \%$ & $5.4 \%$ & $7 \%$ \\
\hline Chloride migration & LMDC & $12.4 \%$ & $25.4 \%$ & $19.4 \%$ & $21.9 \%$ \\
\hline Water content at RH=53.5\% & LaSIE & $14 \%$ & $7 \%$ & Not available & Not available \\
\hline Carbonation depth & $\begin{array}{c}\text { CERIB and } \\
\text { LaSIE }\end{array}$ & $37 \%$ & $35 \%$ & $12 \%$ & $33 \%$ \\
\hline Resistivity & I2M & $17.9 \%$ & $15.6 \%$ & $17.2 \%$ & $18.5 \%$ \\
\hline Porosity & LMT & $7.9 \%$ & $9 \%$ & $4 \%$ & $7 \%$ \\
\hline $\begin{array}{c}\text { Degraded depth after } 210 \\
\text { days of leaching }\end{array}$ & LMT & $10.1 \%$ & $8.1 \%$ & $9.8 \%$ & $9.5 \%$ \\
\hline Permeability & CEA & $22 \%$ & Not available & Not available & Not available \\
\hline
\end{tabular}


In order to perform lifetime simulations related to durability on the basis of reliability approach, it is necessary to characterize the variability of the model parameters by their appropriate probability density function according to the observed statistical distribution. These density functions can be used as initial or prior estimates for the studies where no data are available. They could be updated, for example using Bayesian techniques, when field data will be available by monitoring or specific investigation of a structure.

To determine the most appropriate probability density function that best represent the statistical distribution of the experimental data, an approach by the maximum likelihood estimator (MLE) was used by Oxand $[46,47]$. This technique helps to determine among the various probability functions tested the one that has the most important likelihood, i.e. the one that is best able to represent the distribution of observations. The suitability of the experimental distribution to the chosen function has not been achieved through an adequacy test (Kolmogorov-Smirnov non-parametric test for the equality of continuous, one-dimensional probability distributions for example) but by simple visual verification considering the small amount of data sometimes available. with respect to the MLE principle even if generally, some of them are rarely used to describe physical parameters in civil engineering. The various parameters studied during the experimental campaign were sometimes obtained by different tests and techniques (e.g. the compressive strength of concrete was determined by the experimental device of the contractor and in different research laboratories; permeability was determined using two different procedures). Table 16 summarizes the different probability functions tested and those that are proposed to represent the intrinsic and measurement variability of the different parameters studied during the experimental campaign. 
Table 16 - Summary of the adequacy of the probability density functions tested.

\begin{tabular}{|l|l|l|}
\hline Durability indicator/test & Proposed distribution laws & Other distribution available \\
\hline Compressive strength & Lognormal, Normal, Extreme & Birnbaum-Sanders, Weibull, Gamma, Rice \\
\hline Permeability & Lognormal, Gamma & Normal, Weibull, Log-logistique, Nakagami \\
\hline Resistivity & Lognormal, Gamma & Normal, Weibull, Log-logistic, Nakagami \\
\hline Density & Extreme, Weibull & Logistic, Log-logistic \\
\hline Porosity & Lognormal, Gamma & Birnbaum-Sanders, Log-logistic \\
\hline Leaching & Normal, Lognormal & Birnbaum-Sanders, Extreme, Weibull, Rice \\
\hline Tensile strength & Lognormal, Gamma & Birnbaum-Sanders, Weibull, Rice, Nakagami \\
\hline Young's modulus & Lognormal, Gamma & Birnbaum-Sanders, Logistic, Log-logistic \\
\hline Carbonation depth & Weibull, Normal & Rice \\
\hline Chloride migration coefficient & Lognormal & Birnbaum-Sanders, Gamma \\
\hline Poisson's coefficient & Lognormal, Gamma & Birnbaum-Sanders \\
\hline
\end{tabular}

610 The adequacy procedure based on the maximum likelihood estimator was applied to samples of varying size. The results were interpreted

611 taking into account a rather small number of data for a precise statistical study (depending on the parameter studied, the data processed varied

612 generally between 20 and 40). This may explain the fact that for many parameters, several probability functions seem relatively close without

613 being able to have clear preference for one or the other. For some parameters, due to a very small number of tests carried out, all the available

614 data has been used to fit the statistical distribution even if some of them came from different specimens (this was done for the chloride 615 migration coefficient $D_{\text {nssm }}$ for example, see Figure 24).

616 From a practical point of view, and from the perspective of using these results in the context of reliability analysis for the engineer, it may be

617 wise to use "classical" probability functions with parameters that are easy to estimate rather than others that are more difficult to simulate. In

618 this sense, the lognormal distribution has often appeared as one of the most appropriate, together with the gamma, extreme and normal 
621

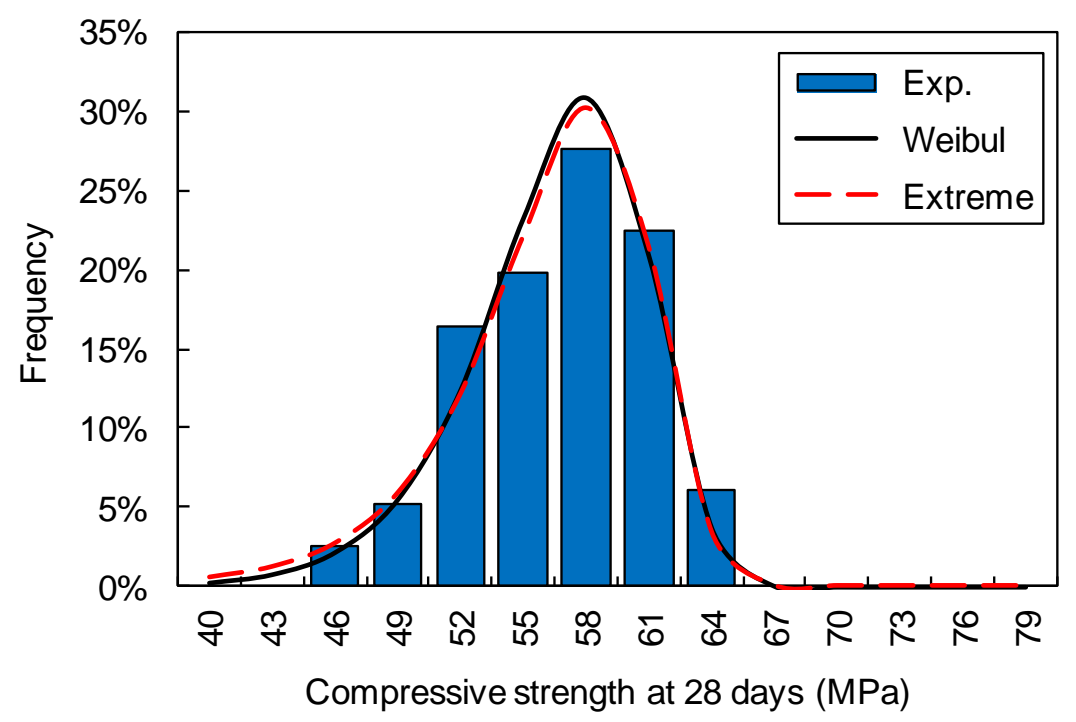




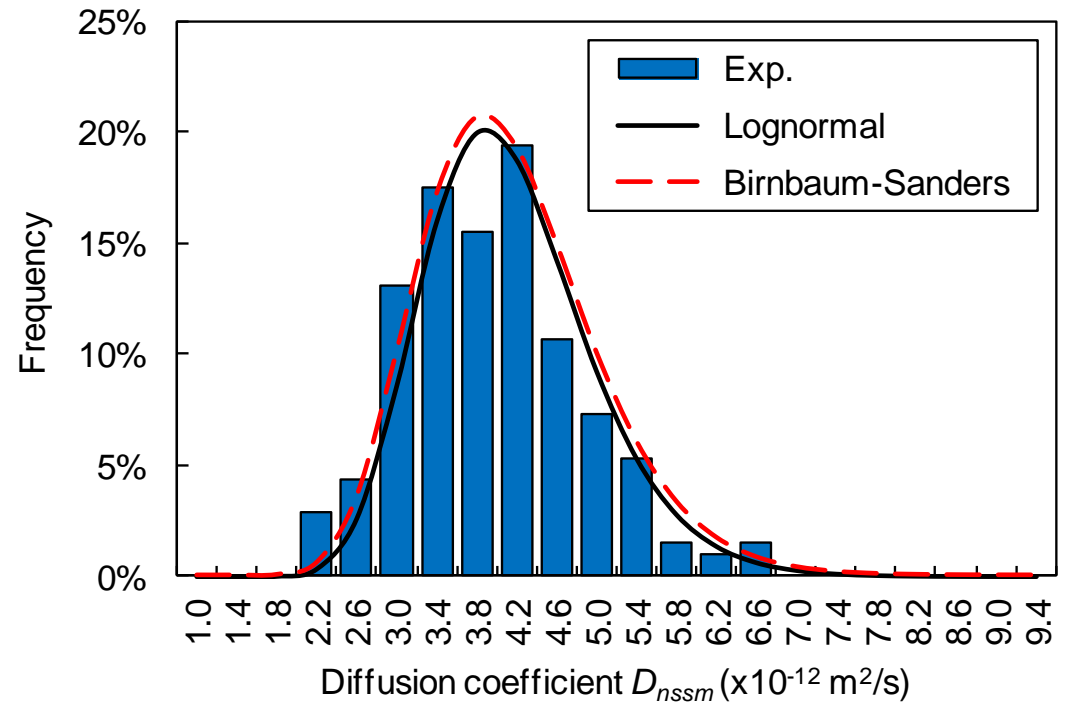

Figure 24 - Probability density and distribution functions for the experimental and theoretical chloride migration coefficient in A1 concrete (sample size: 206).

\section{Conclusion}

One of the main objectives of the APPLET project (work group 1) was to characterize concretes variability for the assessment of reinforced concrete structures durability. In practice, a quantitative insight of concretes variability was obtained through durability tests and indicators. Forty sets of concrete specimens were taken from two different construction sites over a period of one year and sent to the different project partners to have different characterization tests performed. The specimens were prepared on the two construction sites by the site workers: the authors then believed that the results obtained were representative of the variability of the two concrete formulations prepared in industrial 

variability that can be expected for the structural elements concrete: the latter might be higher.

The results obtained do however constitute a unique dataset of reliable and consistent experimental data that can be used to estimate the variability of concrete properties within existing structures. Fitting using suitable probability density functions allows these data to be used as inputs for probabilistic approaches. From a practical point of view, one could select from the database the parameters that are relevant for his parameters with low variability may have a pronounced influence on the outcome and vice versa. For example, in the approach of Muigai et al.

\section{Acknowledgements}

\section{References} approach for assessing reinforced concrete structures lifetime: the applet project, EPJ Web of Conf. 12 (2011) 01004 (2011). 
[2] J-M. Torrenti, P. Dantec, C. BoulayJ-F. Semblat, Projet du processus d'essai pour la détermination du module de déformation longitudinale du béton (in French), Bull. Lab. Ponts Chaussées 220 (1999) 79-81.

[3] S.A. Mirza, M. Hatzinikolas, J.G. McGregor, Statistical descriptions of strength of concrete, ASCE J. Struct. Div. 105 (1979) $1021-1037$.

[4] T. Chmielewski, E. Konopka, Statistical evaluations of field concrete strength." Mag. Concr. Res. 51 (1999) 45-52.

[5] J-M. Torrenti, Vers une approche probabiliste de la durabilité : application au cas de stockage de déchets nucléaires (in French), In: Conference GC'2005, Paris, France, 2005.

[6] F. Cussigh, V. Bonnard, C. Carde, O. Houdusse, Rion-Antirion bridge project - concrete durability for prevention of corrosion risks, in: Toutlemonde et al. (Eds.), proceedings of the International Conference on Concrete Under Severe Conditions (CONSEC'07), Tours, France, 2007, pp. 839-850.

[7] NT Build 492, Concrete, mortar and cement-based repair materials: chloride migration coefficient from non-steady-state migration experiments, Nordtest method, 1999, 8p.

[8] F. Deby, M. Carcassès, A. Sellier, Simplified models for the engineering of concrete formulations in a marine environment through a probabilistic method, Eur. J. Env. Civ. Eng. 16 (2012) 362-374.

[9] F. Deby, M. Carcassès, A. Sellier, Probabilistic approach for durability design of reinforced concrete in marine environment, Cem. Concr. Res. 39 (2009) 466-471.

[10] A. Trabelsi, A. Hamami, R. Belarbi, P. Turcry, A. Aït-Mokhtar, Assessment of the variability of moisture transfer properties of High Performance Concrete from multi-stages drying experiment, Eur. J. Env. Civ. Eng. 16 (2012) 352-361.

[11] R. Belarbi, A. Ait-Mokhtar, M. Qin, O. Omikrine, Development of simplified approach to model the moisture transfer of building materials, Eur. J. Env. Civ. Eng. 10 (2006) 1033-1048.

[12] V. Baroghel-Bouny, Water vapour sorption experiments on hardened cementitious materials. Part II: Essential tool for assessment of transport properties and for durability prediction, Cem. Concr. Res. 37 (2007) 438-454.

[13] K.S.W. Sing, D.H. Everett, R.A.W. Haul, L. Moscou, R.A. Pierotti, J. Rouquérol, T. Siemieniewska, Reporting physisorption data for gas/solid systems, Pure Appl. Chem. 57 (1985) 603-619.

[14] A. Trabelsi, R. Belarbi, P. Turcry, A. Aitt-Mokhtar, Water vapour desorption variability of in situ concrete and effects on drying simulations, Mag. Concr. Res. 63 (2011) 333-342.

[15] P. Turcry, A. Younsi, F. Jacquemot, A. Aitt-Mokhtar, P. Rougeau, Influence of in situ concrete variability on accelerated carbonation test, Eur. J. Env. Civ. Eng. 16 (2012) 288-297.

[16] G.G. Litvan, A. Meyer, Carbonation of Granulated Blast Furnace Slag cement concrete during twenty years of field exposures, in: Malhotra (Ed.) proceedings of the $5^{\text {th }}$ international conference on fly ash, silica fume, slag and natural pozzolans in concrete, Madrid, Spain, 1986, ACI SP-91, pp. 1445-1462.

[17] M. Maage, Carbonation in concrete made of blended cements, Mater. Res. Symp. Proc. 65 (1986) 193-198.

[18] C. Andrade, C. Alsonso, A. Arteaga, P. Tanner, Methodology based on the electrical resistivity for calculation of reinforcement service life, in: Malhotra (Ed.) proceedings of the $5^{\text {th }}$ CANMET/ACI International Conference on Durability of Concrete, Barcelona, Spain, 2000, pp. 899915.

[19] E.J. Garboczi, Permeability, diffusivity and microstructural parameters: a critical review, Cem. Concr. Res. 20 (1990) $591-601$. 
[20] O. Francy, Modélisation de la pénétration des ions chlorures dans les mortiers partiellement saturés en eau (in French), Ph.D. thesis, Paul Sabatier university, Toulouse, France, 1998, 171p.

[21] F. Rajabipour, W.J. Weiss, D.M. Abraham, Insitu electrical conductivity measurements to assess moisture and ionic transport in concrete (a discussion of critical features that influence the measurements), in: Weiss et al. (Eds) proceedings of the $1^{\text {st }}$ international RILEM symposium on Advances in Concrete through Science and Engineering, March 21-26, 2004, Evanston, 18p.

[22] V. Baroghel-Bouny, Conception des bétons pour une durée de vie donnée des ouvrages - indicateur de durabilité (in French), Document Scientifique et Technique AFGC, 2004, 252p.

[23] J-F. Lataste, T. de Larrard, F. Benboudjema, J. Séménadisse, Electrical resistivity variability of two concretes: protocol study in laboratory and assessment on site, Eur. J. Env. Civ. Eng. 16 (2012) 298-310.

[24] I.L.H. Hansson, C.M. Hansson, Electrical resistivity measurements of Portland cement-based materials, Cem. Concr. Res. 13 (1983) 675-683.

[25] AFPC-AFREM, Durabilité des bétons - Méthodes recommandées pour la mesure des grandeurs relatives à la durabilité (in French), proceedings of the technical meeting AFPC-AFREM, december 1997, Toulouse, France, 1997.

[26] F. Zhang, T. Rougelot, N. Burlion, Porosity of concrete: Influence of test conditions and material variability, Eur. J. Env. Civ. Eng. 16 (2012) 311-321.

[27] T. de Larrard, S. Poyet, M. Pierre, F. Benboudjema, P. Le Bescop, J-B. Colliat, J-M. Torrenti, Modelling the influence of temperature on accelerated leaching in ammonium nitrate, Eur. J. Env. Civ. Eng. 16 (2012) 322-335.

[28] S. Poyet, P. Le Bescop, M. Pierre, L. Chomat, C. Blanc, Accelerated leaching using ammonium nitrate (6M): influence of test conditions, Eur. J. Env. Civ. Eng. 16 (2012) 336-351.

[29] F.M. Lea, The action of ammonium salts on concrete, Mag. Concr. Res. 17 (1965) 115-116.

[30] C. Le Bellego, Couplage chimie-mécanique dans les structures en béton attaquées par l'eau: étude expérimentale et analyse numérique (in French), Ph.D. thesis, Ecole Normale Supérieure de Cachan, France, 2001, 236p.

[31] T. de Larrard, F. Benboudjema, J-B. Colliat, J-M. Torrenti, F. Deleruyelle, Concrete calcium leaching at variable temperature: experimental data and numerical model inverse identification, Comput. Mater. Sci. 49 (2010) 35-45.

[32] M. Buil, E. Revertégat, J. Oliver, A model for the attack of pure water or undersaturated lime solutions on cement, In: Gilliam \& Wiles (Eds.) Stabilization and Solidification of Hazardous Radioactive and Mixed Wastes, ASTM STP 1123 1992, pp. 227-241.

[33] M. Mainguy, C. Tognazzi, J-M. Torrenti, F. Adenot, Modelling of leaching in pure cement paste and mortar, Cem. Concr. Res. 30 (2000) $83-$ 91.

[34] V.H. Nguyen, B. Nedjar, H. Colina, J-M. Torrenti, A separation of scales homogenisation analysis for the modelling of calcium leaching in concrete, Comput. Methods Appl. Mech. Eng. 195 (2006) 7196-7210.

[35] J.J. Kollek, The determination of the permeability of concrete to oxygen by the Cembureau method - a recommendation, Mater. Struct. 22 (1989) 225-230.

[36] C. Gallé, J-F. Daïan, Gas permeability of unsaturated cement-based materials: application of a multi-scale network model, Mag. Concr. Res. 52 (2000) 251-263.

[37] C. Gallé, J. Sercombe, Permeability and pore-structure evolution for silico-calcareous and hematite high-strength concretes submitted to high temperatures, Mater. Struct. 34 (2001) 619-628. 


\begin{tabular}{|c|c|c|}
\hline Name & Density function & Parameters \\
\hline Birnbaum-Sanders & $f(x)=\frac{1}{\gamma B \sqrt{8 \pi}}\left[\left(\frac{B}{x}\right)^{\frac{1}{2}}+\left(\frac{B}{x}\right)^{\frac{3}{2}}\right] \exp \left[-\frac{1}{2 \gamma^{2}}\left(\frac{x}{b}+\frac{B}{x}-2\right)\right.$ & $\begin{array}{c}x>0 \quad y, b>0 \\
\text { Mean value }=\left(1+\frac{v^{2}}{2}\right) B \\
\text { Standard deviation }=\nu B \sqrt{1+\frac{5}{4} \nu^{2}}\end{array}$ \\
\hline Exponential & $f(x)=\lambda \exp (-\lambda x)$ & $\begin{array}{c}x \geq 0 \\
\text { Mean value }=\lambda^{-1} \\
\text { Standard deviation }=\lambda^{-1}\end{array}$ \\
\hline
\end{tabular}

[38] M.C.R. Farage, J. Sercombe, C. Gallé, Rehydration and microstructure of cement paste after heating at temperatures up to $300^{\circ} \mathrm{C}$, Cem Concr. Res. 33 (2003), 1047-1056.

[39] P. Kalifa, G. Chéné, C. Gallé, High-temperature behaviour of HPC with polypropylene fibres: from spalling to microstructure, Cem. Concr. Res. 31 (2000) 1487-1499.

[40] P.A.M. Basheer, Permeation analysis, In: Ramachandran \& Beaudouin (Eds), Handbook of analytical techniques in concrete science and technology, Noyes Publications, Park Ridge, New Jersey, USA, 2001, pp. 658-737.

[41] L.J. Klinkenberg, The permeability of porous media to liquid and gases, Drill. Prod. Pract. Am. Pet. Inst. (1941) $200-214$.

[42] A.M. Vaysburd, C.D. Brown, B. Bissonnette, P.H. Emmons, Realcrete versus Labcrete, Concr. Int. 26 (2004) $90-94$.

[43] S. Poyet, X. Bourbon, Experimental investigation of concrete packages for radioactive waste management: permeability and influence of junctions, Transp. Porous Med. 95 (2012) 55-70.

[44] H.S. Wong, A.M. Pappas, R.W. Zimmerman, N.R. Buenfeld, Effect of entrapped air voids on the microstructure and mass transport properties of concrete, Cem. Concr. Res. 41 (2011) 1067-1077.

[45] H. Loosveldt, Z. Lafhaj, F. Skoczylas, Experimental study of gas and liquid permeability of a mortar, Cem. Concr. Res. 32 (2002) $1357-1363$.

[46] R.A. Fisher, On the mathematical foundations of theoretical statistics, Philosoph. T. Roy. Soc. A 222 (1922) $309-368$.

[47] A.W.F. Edwards, Likelihood, Cambridge University Press, 1972, 243p.

[48) R. Muigai, P. Moyo, M. Alexander, Durability design of reinforced concrete structures: a comparison of the use of durability indexes in the deemed-to-satisfy approach and the full-probabilistic approach, Mater. Struct. 45 (2012) 1233-1244.

\section{Appendix: probability density functions}




\begin{tabular}{|c|c|c|}
\hline Extreme & $f(x)=\frac{1}{\sigma} \exp \left(\frac{x-\mu}{\sigma}\right) \exp \left[-\exp \left(\frac{x-\mu}{\sigma}\right)\right]$ & $\begin{array}{c}\text { Mean value }=\mu+\gamma \sigma \\
\text { (where } \gamma \text { is the Euler-Mascheroni constant } \approx 0.577 \text { ) } \\
\text { Standard deviation }=\frac{\pi}{\sqrt{6}} \sigma\end{array}$ \\
\hline Gamma & $f(x)=x^{k-1} \frac{\exp \left(-\frac{x}{\vartheta}\right)}{\Gamma(k) \vartheta^{k}}$ & $\begin{array}{c}x \geq 0 \quad k, \vartheta>0 \\
\Gamma \text { is the gamma function } \\
\text { Mean value }=k \vartheta \\
\text { Standard deviation }=\sqrt{k \vartheta}\end{array}$ \\
\hline \multirow[t]{2}{*}{ Log-logistic } & \multirow{2}{*}{$f(x)=\frac{\beta}{\alpha}\left(\frac{x}{\alpha}\right)^{\beta-1}\left[1+\left(\frac{x}{\alpha}\right)^{\beta}\right]^{-2}$} & $\begin{array}{c}x \geq 0 \quad \alpha, b>0 \\
\text { Mean value }=\frac{\pi \alpha}{b \sin \left(\frac{\pi}{b}\right)}\end{array}$ \\
\hline & & Standard deviation $=\alpha \sqrt{\frac{2 \pi}{B \sin \left(\frac{2 \pi}{b}\right)}}-\frac{\pi^{2}}{B^{2} \sin \left(\frac{\pi}{B}\right)}$ \\
\hline Logistic & $f(x)=\frac{1}{s} \exp \left(-\frac{x-\mu}{s}\right)\left[1+\exp \left(-\frac{x-\mu}{s}\right)\right]^{-2}$ & $\begin{array}{c}s>0 \\
\text { Mean value }=\mu \\
\text { Standard deviation }=\frac{\pi s}{\sqrt{3}}\end{array}$ \\
\hline Lognormal & $f(x)=\frac{1}{x \sigma \sqrt{2 \pi}} \exp \left[-\frac{(\ln (x)-\mu)^{2}}{2 \sigma^{2}}\right]$ & $\begin{aligned} x \geq 0 & \\
\text { Mean value } & =\exp \left[\frac{1}{2}\left(\mu+\sigma^{2}\right)\right] \\
\text { Standard deviation } & =\exp \left(\mu+\frac{\sigma^{2}}{2}\right) \sqrt{\exp \left(\sigma^{2}\right)-1}\end{aligned}$ \\
\hline Nakagami & $f(x)=\frac{2 \mu^{\mu}}{\Gamma(\mu) \omega^{\mu}} x^{2 \mu-1} \exp \left(-\frac{\mu}{\omega} x^{2}\right)$ & $\begin{array}{c}x>0 \quad \mu \geq 0.5 \quad \omega>0 \\
\text { Mean value }=\frac{\Gamma(\mu+0.5)}{\Gamma(\mu)} \sqrt{\frac{\omega}{\mu}} \\
\Gamma \text { is the gamma function }\end{array}$ \\
\hline
\end{tabular}




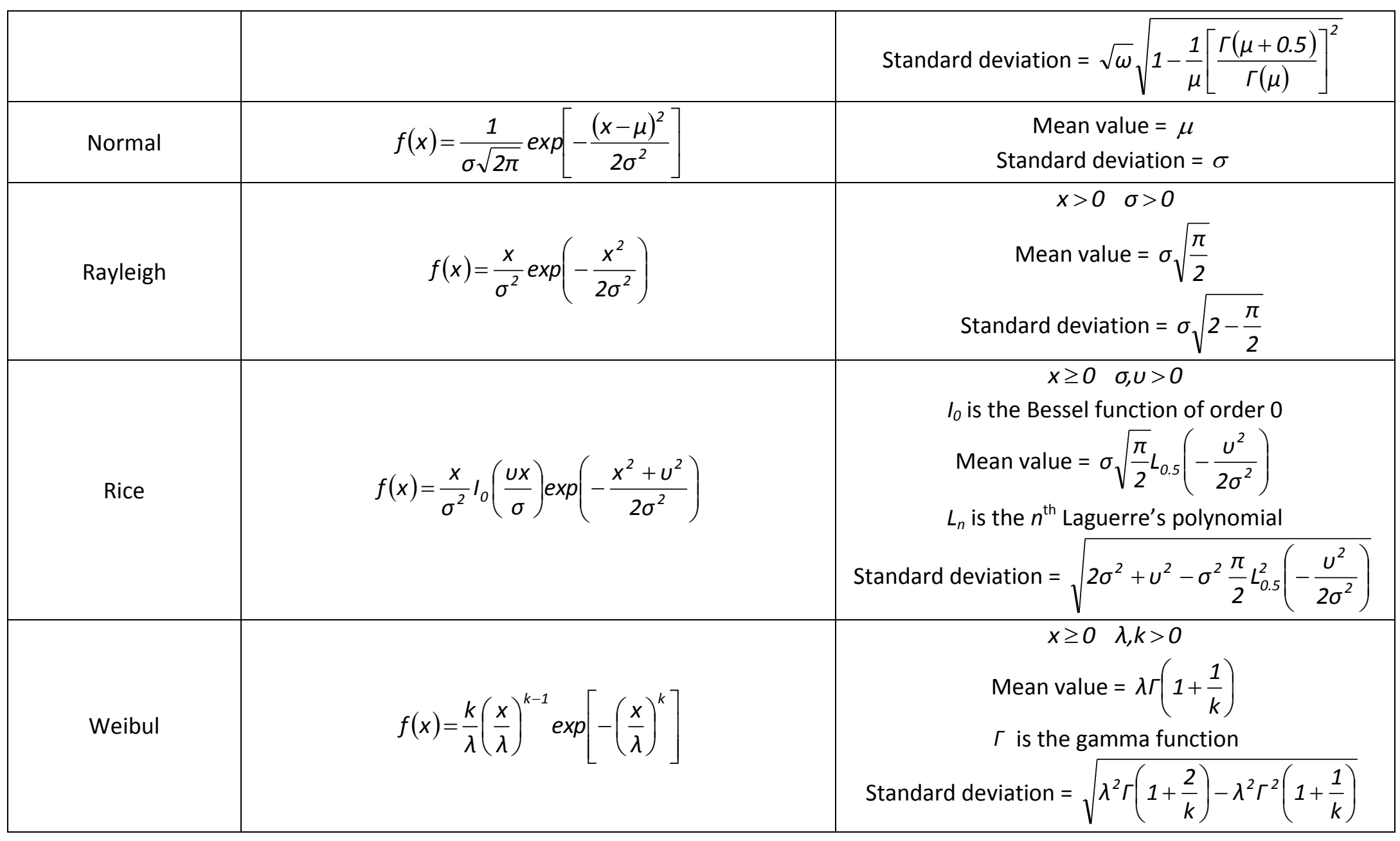

